\title{
An Experimental Investigation on the Failure Behavior of a Notched Concrete Beam Strengthened with Carbon Fiber-Reinforced Polymer
}

\author{
Xia Huang, ${ }^{1}$ Jian Wang, ${ }^{1}$ Feng Zhang, ${ }^{1}$ Song-shan Niu, ${ }^{2}$ and Jun Ding ${ }^{1}$ \\ ${ }^{1}$ College of Mechanical Engineering, Chongqing University of Technology, Chongqing 400054, China \\ ${ }^{2}$ China Merchants Chongqing Communications Technology Research \& Design Institute Co. Ltd., Chongqing 400067, China \\ Correspondence should be addressed to Jun Ding; dingjunawen@126.com
}

Received 11 June 2015; Revised 21 August 2015; Accepted 24 August 2015

Academic Editor: Osman Gencel

Copyright ( $\odot 2015$ Xia Huang et al. This is an open access article distributed under the Creative Commons Attribution License, which permits unrestricted use, distribution, and reproduction in any medium, provided the original work is properly cited.

\begin{abstract}
This paper presents an experiment investigation on the failure behavior of a notched concrete beam reinforced with CFRP, by exploring the influences of the length, thickness, and CFRP bonding methods on the ultimate bearing capacity and failure mode. The interfacial shear stress has first been analytically derived and parametric analyses are then made to predict the failure mode. The experiment observation finds that failure mode significantly depends on CFRP length. The brittle fracture occurs only for nonstrengthened beams; the shear failure I mode mainly occurs when CFRP laminate is $100 \mathrm{~mm}$ long; the shear failure II mode mainly occurs when CFRP laminate is $200 \mathrm{~mm}$ long; and the delamination failure mode mainly occurs when CFRP laminate is $350 \mathrm{~mm}$ long. Meanwhile, the thickness and the bonding methods of CFRP also influence the final failure modes in terms of CFRP length. The measurement on ultimate load shows that an increase in the length of CFRP up to $200 \mathrm{~mm}$ significantly improves the bearing capacity of the reinforced beam. A comparison between a theoretical analysis and the experimental observation shows a good agreement in terms of failure modes indicating the accuracy and the validity of the experiment.
\end{abstract}

\section{Introduction}

The rapid development of the economy of the world has resulted in an unprecedented development of the urban infrastructure construction. Along with this growth is the rapid expansion of e-commerce and logistics, which in turn possess considerable challenges to the existing highway and bridge infrastructures. Highways and bridges are subjected to increasing levels of cyclic loading and overloading. Furthermore, these concrete structures often suffer from pavement cracks, fractures, and other similar damage, to aggravate the already aging structures. Yet, some of these structures have adequate bearing capacities and must therefore be repaired and reinforced instead of being rebuilt to maintain the requirements for safety, serviceability, and durability $[1,2]$.

In the field of structural engineering, the common methods for repairing and reinforcing damaged structures mainly include section enlargement, steel-encasing, prestressed reinforcement, sticking steel plate, and glass fiber-reinforced plastic strengthening. However, these methods have a number of technical defects and are sometimes associated with poor corrosion resistance. With the advancement in materials science and technology, carbon fiber-reinforced polymer (CFRP) is increasingly being used to reinforce and repair concrete structures due to its high tensile strength, high stiffness, good fatigue resistance, and corrosion resistance. In addition, they do not add to the self-weight of the structure being reinforced or cause chain reinforcement reaction among other structures in the architecture [3-6]. Thus, CFRP has broad application prospects for the retrofitting and strengthening of reinforced concrete (RC) beams and steel beams, both of them similar in flexural behavior.

A review of previous studies shows that fiber-reinforced polymers, including CFRP, GFRP, and other ordinary FRPs (they are similar in essence other than their constituent materials), have been effectively used for strengthening the flexural and shear resistance of the reinforced concrete beams and steel beams. Edberg et al. [7] reported an experimental investigation in which five different configurations of CFRP 
and GFRP were used to attach them on the tensile side of small-scale RC beams. Mazzotti et al. [8] presented an experiment study on FRP-concrete delamination, in which specimens with varying bonded lengths and plate widths were tested. The results showed an increase in the maximum shear stress with decreasing plate width; however, no significant effect of plate width was observed on fracture energy and delamination. Nakaba et al. [9] studied the mechanical behavior of the adhesive layer between a CFRP layer and concrete. They conducted a single-sided shear failure test on CFRP to clarify the relationship between the shear stress of the bond layer and the slip of the CFRP. The stiffness of CFRP laminate was found to influence the bonding force and the stress distribution on the bonding interface. Malek et al. [10] studied the basic mechanisms of concrete beams reinforced with fiber-reinforced plates (FRPs). They proposed a model for predicting the shear and normal stresses between a fiber composite plate and the undersurface of a concrete beam and obtained the analytical solution for the shear and normal stresses near the end of the fiber plate. Saadatmanesh and Ehsani [11] studied glass fiber plate-reinforced (GFRP) concrete beams to investigate the responses of different cross sections of a concrete beam under four-point bending load. The results showed that GFRP can significantly increase the bending strength of a cross section of a concrete beam under tension and that even a low reinforcement ratio produces a strong reinforcement effect. Meanwhile, GFRP-strengthened concrete beams may result in reduced plasticity of the beam structures. Saadatmanesh and Mohammad [12] also studied the influence on the reinforcement effect of the bonded area, the stiffness and the strength of GFRPs, the compressive strength of concrete, and the reinforcement ratio. The conclusion was consistent with that of [11]. While an increased compressive strength of concrete had no obvious effect on the bending strength of the unreinforced beams, an increase in concrete compressive strength significantly increased the bending strength of the reinforced beams. Sierra-Ruiz et al. [13] studied the shear stress distribution between concrete beams and CFRPs under three conditions, namely, pure shear, pure tension, and pure bending, and analyzed several important factors that affect the shear stress distribution under the three conditions. They also determined that the maximum shear stress is directly related to the tensile strength of a fiber composite plate.

Some studies have focused on the prediction and identification of CFRP failure modes. Buyukozturk et al. [14] mentioned that use of FRP to strengthen and repair structural members has become a mainstream application on structural engineering even though it had not been emerged for a long time. A particular emphasis was made on the fact that the debonding failure could significantly decrease the effectiveness of the repair application which deserves a concentration of research efforts. Colombi [15] studied the delamination failure of steel beams reinforced with FRP. A simplified fracture mechanics-based approach was illustrated for the edge delamination, thus, contributing to establish a fracture mechanics-based failure criterion for the delamination failure. Benachour et al. [16] derived a closed-form rigorous solution based on linear elasticity for the interfacial stress in a

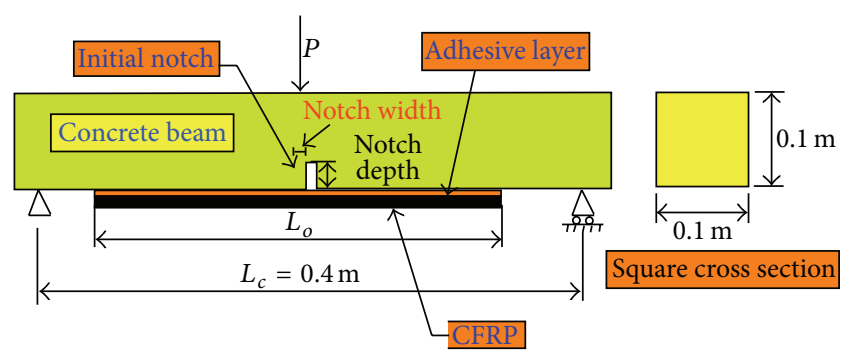

FIGURE 1: The geometrical configuration for the reinforced concrete beam.

simply supported beam reinforced with CFRP and subjected to a uniformly distributed load, single point load, and two symmetric point loads. The results showed that a high concentration of both shear and normal stresses occurred at the ends of the CFRP layer, thus, causing a premature failure mode at the locations.

The present work is aimed at understanding the effect of CFRP bonded to the concrete beam on the strength enhancement and the failure modes of the beam. The concrete beam is embedded with an initial notch at the central part of the beam so as to simulate the damage, defect, or crack in beam structures in need of repairing. This paper investigates the influences of the length and thickness of CFRP laminates and the methods of bonding CFRP on the ultimate load capacity and the final failure modes of the reinforced beam structure. Based on the experimental results, a parametric study is performed to derive an equation for the interfacial shear stress. Finally, a calculation is made to determine an optimal reinforcement ratio that can provide a reference for improving the reinforcement technology and maximizing the potential of CFRP-strengthening method.

\section{Theoretical Analysis}

2.1. Geometrical Configuration of the Notched Concrete Beam. A concrete beam containing an initial notch of rectangular shape is considered to represent the engineering structures that are in need of repairing. Figure 1 shows the geometric configuration of the notched concrete beam as a simplification of a three-point bending beam model [3-5, 8-11]. The reinforced structure consists of three layers: (a) the plain concrete beam of square cross section with an initial notch at the middle of the beam (marked as light green color in Figure 1), (b) a CFRP sheet (marked as black color), and (c) a very thin layer of adhesive located at the interface between concrete beam and CFRP (marked as orange color). Given that the plain concrete beam is much thicker than the CFRP sheet and the adhesive layer (epoxy resin), the following assumptions are made: (1) The deformation of the concrete beam and that of the carbon fiber plate comply with the assumption for the plane cross section; thus, the strains of the concrete beam are linearly distributed along the height of the reinforced beam. However, since the CFRP thickness is very small, the variation in the strain along the thickness direction can be ignored, and the strain in the thickness direction of the CFRP 


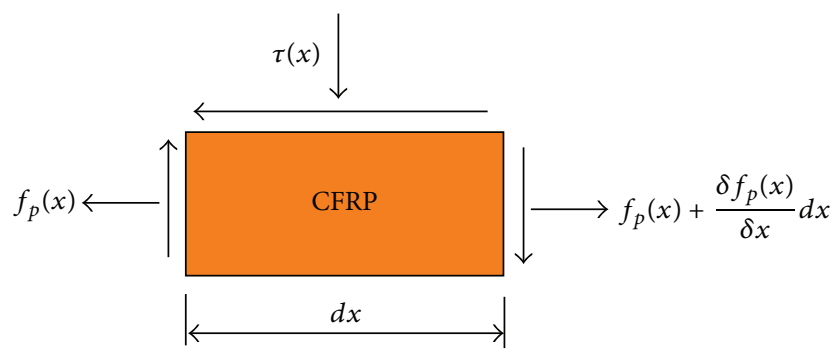

FIGURE 2: The force equilibrilum of CFRP of $d x$.

layer is constant. (2) The principles of small deformation theory and the basic theory of solid mechanics are applicable. (3) No sliding occurs at the interface between CFRP and the concrete beam (perfect bond condition). (4) Both concrete and CFRP are considered as linear elastic materials.

2.2. Derivation for the Shear Stress. The shear stress at the interface between CFRP and adhesive layer has been considered as the key factor that affects the final failure mode of the reinforced concrete structures [3-5, 10-13]. Consequently, it is necessary to obtain an analytical solution to the interfacial shear stress at the end of the CFRP plate. We consider the force equilibrium of an infinitesimal CFRP with a length of $d x$ (Figure 2) according to its equilibrium in the horizontal direction.

The following equation can be obtained:

$$
d f_{p}(x) t_{p}-\tau(x) d x=0
$$

where $f_{p}(x)$ is the tensile stress acting on the CFRP, $t_{p}$ is the thickness of the CFRP, and $\tau(x)$ is the shear stress at the interface between the CFRP and the adhesive layer.

Thus, the expression for shear stress $\tau(x)$ can be obtained:

$$
\tau(x)=\frac{d f_{p}(x)}{d x} t_{p}
$$

In addition,

$$
\begin{aligned}
\tau(x) & =G_{a} \gamma_{a} \\
\gamma_{a} & =\frac{d u}{d y}+\frac{d v}{d x}
\end{aligned}
$$

By combining (2), (3), and (4), the following equation can be obtained:

$$
\frac{d f_{p}(x)}{d x}=\frac{G_{a}}{t_{p}}\left(\frac{d u}{d y}+\frac{d v}{d x}\right)
$$

where $u$ and $v$ represent the horizontal and vertical displacements of the adhesive layer, respectively, and $G_{a}$ is the shear modulus of the adhesive.
By differentiating both ends of (5), the following are obtained:

$$
\frac{d^{2} f_{p}(x)}{d x^{2}}=\frac{G_{a}}{t_{p}}\left(\frac{d^{2} u}{d x d y}+\frac{d^{2} v}{d x^{2}}\right) .
$$

According to the principles of solid mechanics, the following equation can be obtained for concrete:

$$
\frac{1}{\rho}=\frac{M}{E_{c} I_{c}}=\frac{d^{2} v}{d x^{2}},
$$

where $\rho$ is the curvature radius of the reinforced concrete beam after deformation, $E_{c}$ is its elastic modulus, $I_{c}$ is the inertia moment of the cross section of the concrete beam, and $M$ is the bending moment of the concrete beam. $d^{2} u / d x d y$ can be expressed as follows:

$$
\frac{d^{2} u}{d x d y}=\frac{1}{t_{a}}\left(\varepsilon_{p}-\varepsilon_{c}\right),
$$

where $t_{a}$ is the thickness of the adhesive and $\varepsilon_{p}$ and $\varepsilon_{c}$ are the strains of the CFRP and the concrete beam, respectively.

By substituting (7) and (8) into (6), the following are obtained:

$$
\frac{d^{2} f_{p}(x)}{d x^{2}}=\frac{G_{a}}{t_{p}}\left(\frac{\varepsilon_{p}}{t_{a}}-\frac{\varepsilon_{c}}{t_{a}}+\frac{M}{E_{c} I_{c}}\right) .
$$

Equation (7) indicates that $M / E_{c} I_{c}$ is equivalent to the inverse of the curvature radius of the concrete beam after deformation. Given that concrete is usually considered as a brittle material, the concrete beam is assumed to have a large curvature radius during deformation. Thus, $M / E_{c} I_{c}$ is very small, and its influence on the result can be ignored. $M / E_{c} I_{c}$ can then be omitted to obtain the following:

$$
\frac{d^{2} f_{p}(x)}{d x^{2}}=\frac{G_{a}}{t_{p}}\left(\varepsilon_{p}-\varepsilon_{c}\right) .
$$

According to the constitutive relation of the CFRP and the concrete beam, both $\varepsilon_{p}=f_{p}(x) / E_{p}$ and $\varepsilon_{p}=f_{p}(x) / E_{p}$ are valid. By substituting them into the equation and by organizing this equation, the following can be obtained:

$$
\frac{d^{2} f_{p}(x)}{d x^{2}}-\frac{G_{a}}{t_{a} t_{p}} \frac{f_{p}(x)}{E_{p}}+\frac{G_{a}}{t_{a} t_{p}} \frac{f_{c}(x)}{E_{c}}=0 .
$$

According to the theory of beam, tensile stress at any point in the beam can be expressed as follows:

$$
f_{c}(x, \bar{y})=\frac{M_{c}(x) \cdot \bar{y}}{I_{c}},
$$

where $\bar{y}$ is the vertical distance of the point on the beam from the neutral plane.

Given the assumptions made in Section 2.1, the influence of the CFRP on the position of the neutral plane of the concrete beam can be ignored. Thus, the distance of the bottom 
surface contacting the glue line from the neutral plane is as follows:

$$
\bar{y}=\frac{t_{c}}{2}
$$

where $t_{c}$ is the height of the concrete beam.

The following is the bending moment of the concrete beam:

$$
M_{c}(x)= \begin{cases}\frac{p}{2}\left(x+L_{0}\right) & \left(0 \leq x<\frac{L_{p}}{2}\right) \\ \frac{p}{2}\left(L_{c}-x-L_{0}\right) & \left(\frac{L_{p}}{2} \leq x \leq L_{p}\right)\end{cases}
$$

where $L_{c}$ is the span of the three-point bending concrete beam, $L_{p}$ is the length of the CFRP bonded at the bottom of the concrete beam, the origin of the coordinate in the $X$ direction is the starting point of the CFRP, $P$ is the external load, and $L_{0}$ is the distance from the support of the concrete beam to the starting point of the CFRP.

The expression of the tensile stress at the bottom surface of the concrete beam can be obtained by substituting (13) to (12):

$$
L_{0}=\frac{\left(L_{c}-L_{p}\right)}{2} \text {. }
$$

The normal stress at the bottom of the concrete beam can be obtained by substituting (13) and (14) into (12):

$$
f_{c}(x)= \begin{cases}\frac{P t_{c}}{4 I_{c}}\left(x+L_{0}\right) & \left(0 \leq x<\frac{L_{p}}{2}\right) \\ \frac{P t_{c}}{4 I_{c}}\left(L_{c}-x-L_{0}\right) & \left(\frac{L_{p}}{2} \leq x \leq L_{p}\right) .\end{cases}
$$

The control equation of the tensile stress distribution $f_{p}(x)$ in the CFRP can be obtained by substituting (16) to (11):

$$
\begin{aligned}
& \frac{d^{2} f_{p}(x)}{d x^{2}}-\frac{G_{a}}{t_{a} t_{p}} \cdot \frac{f_{p}(x)}{E_{p}}+\frac{G_{a}}{t_{a} t_{p}} \cdot \frac{P t_{c}\left(x+L_{0}\right)}{4 I_{c} E_{c}}=0 \\
& \quad\left(0 \leq x<\frac{L_{p}}{2}\right) \\
& \frac{d^{2} f_{p}(x)}{d x^{2}}-\frac{G_{a}}{t_{a} t_{p}} \cdot \frac{f_{p}(x)}{E_{p}}+\frac{G_{a}}{t_{a} t_{p}} \cdot \frac{P t_{c}\left(L_{c}-x-L_{0}\right)}{4 I_{c} E_{c}} \\
& =0 \quad\left(\frac{L_{p}}{2} \leq x<L_{p}\right) .
\end{aligned}
$$

After solving the differential equation, the expression of $f_{p}(x)$ can be obtained:

$$
f_{p}(x)= \begin{cases}C_{1} e^{-\sqrt{G_{a} / E_{p} t_{a} t_{p}} x}+C_{2} e^{\sqrt{G_{a} / E_{p} t_{a} t_{p}} x}+\frac{E_{p} t_{c} P x}{4 E_{c} I_{c}}+\frac{E_{p} t_{c} P L_{0}}{4 E_{c} I_{c}} & \left(0 \leq x<\frac{L_{p}}{2}\right) \\ C_{3} e^{-\sqrt{G_{a} / E_{p} t_{a} t_{p}} x}+C_{4} e^{\sqrt{G_{a} / E_{p} t_{a} t_{p}} x}-\frac{E_{p} t_{c} P x}{4 E_{c} I_{c}}+\frac{E_{p} t_{c} P\left(L_{c}-L_{0}\right)}{4 E_{c} I_{c}} & \left(\frac{L_{p}}{2} \leq x<L_{p}\right) .\end{cases}
$$

The expression of the shear stress can be obtained by differentiating the equation and substituting it into (2):

$$
\tau(x)=\left\{\begin{array}{l}
-C_{1} \sqrt{\frac{G_{a} t_{p}}{E_{p} t_{a}}} e^{-\sqrt{G_{a} / E_{p} t_{a} t_{p}} x}+C_{2} \sqrt{\frac{G_{a} t_{p}}{E_{p} t_{a}}} e^{\sqrt{G_{a} / E_{p} t_{a} t_{p}} x}+\frac{E_{p} t_{c} t_{p} P}{4 E_{c} I_{c}} \quad\left(0 \leq x<\frac{L_{p}}{2}\right) \\
-C_{3} \sqrt{\frac{G_{a} t_{p}}{E_{p} t_{a}}} e^{-\sqrt{G_{a} / E_{p} t_{a} t_{p}} x}+C_{4} \sqrt{\frac{G_{a} t_{p}}{E_{p} t_{a}}} e^{\sqrt{G_{a} / E_{p} t_{a} t_{p}} x}-\frac{E_{p} t_{c} t_{p} P}{4 E_{c} I_{c}} \quad\left(\frac{L_{p}}{2} \leq x<L_{p}\right) .
\end{array}\right.
$$

The integration constants $C_{1}, C_{2}, C_{3}$, and $C_{4}$ in the preceding equation can be determined according to the following boundary conditions:

$$
\begin{aligned}
0 & \leq x<\frac{L_{p}}{2}, \\
f_{p}(0) & =0, \\
\tau\left(\frac{L_{p}}{2}\right) & =0,
\end{aligned}
$$

$$
\begin{aligned}
\frac{L_{p}}{2} & \leq x<L_{p}, \\
f_{p}\left(L_{p}\right) & =0, \\
\tau\left(\frac{L_{p}}{2}\right) & =0 .
\end{aligned}
$$


The following two equations can be obtained by substituting the boundary conditions into (18) and (19):

$$
\begin{aligned}
& C_{1}+C_{2}+\frac{E_{p} t_{c} P L_{0}}{4 E_{c} I_{c}}=0, \\
& -C_{1} \sqrt{\frac{G_{a} t_{p}}{E_{p} t_{a}}} e^{-\sqrt{G_{a} / E_{p} t_{a} t_{p}} \cdot L_{p} / 2} \\
& +C_{2} \sqrt{\frac{G_{a} t_{p}}{E_{p} t_{a}}} e^{\sqrt{G_{a} / E_{p} t_{a} t_{p}} \cdot L_{p} / 2}+\frac{E_{p} t_{c} t_{p} P}{4 E_{c} I_{c}}=0, \\
& C_{3} e^{-\sqrt{G_{a} / E_{p} t_{a} t_{p}} \cdot L_{p}}+C_{4} e^{\sqrt{G_{a} / E_{p} t_{a} t_{p}} \cdot L_{p}}-\frac{E_{p} t_{c} P L_{p}}{4 E_{c} I_{c}} \\
& +\frac{E_{p} t_{c} P\left(L_{c}-L_{0}\right)}{4 E_{c} I_{c}}=0, \\
& -C_{3} \sqrt{\frac{G_{a} t_{p}}{E_{p} t_{a}}} e^{-\sqrt{G_{a} / E_{p} t_{a} t_{p}} \cdot L_{p} / 2} \\
& +C_{4} \sqrt{\frac{G_{a} t_{p}}{E_{p} t_{a}}} e^{\sqrt{G_{a} / E_{p} t_{a} t_{p}} \cdot L_{p} / 2}-\frac{E_{p} t_{c} t_{p} P}{4 E_{c} I_{c}}=0 .
\end{aligned}
$$

Supposing $A=G_{a} / E_{p} t_{a} t_{p}$ and $B=E_{p} t_{c} / 4 E_{c} I_{c}$, the above boundary conditions can be simplified as the following:

$$
\begin{array}{r}
C_{1}+C_{2}+B P L_{0}=0, \\
-C_{1} \sqrt{A} e^{-\sqrt{A} \cdot L_{p} / 2}+C_{2} \sqrt{A} e^{\sqrt{A} \cdot L_{p} / 2}+B P=0,
\end{array}
$$

$$
\begin{aligned}
& C_{3} e^{-\sqrt{A} \cdot L_{p}}+C_{4} e^{\sqrt{A} \cdot L_{p}}-B P L_{p}+B P\left(L_{c}-L_{0}\right)=0, \\
& -C_{3} \sqrt{A} e^{-\sqrt{A} \cdot L_{p} / 2}+C_{4} \sqrt{A} e^{\sqrt{A} \cdot L_{p} / 2}-B P=0 .
\end{aligned}
$$

Then, the values for the integration constants $C_{1}, C_{2}, C_{3}$, and $C_{4}$ can be solved, respectively:

$$
\begin{aligned}
& C_{1}=\frac{e^{L_{p} \sqrt{A} / 2}-L_{0} \sqrt{A} e^{L_{p} \sqrt{A}}}{\sqrt{A}\left(1+e^{L_{p} \sqrt{A}}\right)} B P ; \\
& C_{2}=-\frac{e^{L_{p} \sqrt{A} / 2}+L_{0} \sqrt{A}}{\sqrt{A}\left(1+e^{L_{p} \sqrt{A}}\right)} B P, \\
& C_{3}=-\frac{e^{L_{p} \sqrt{A}}\left(e^{L_{p} \sqrt{A} / 2}-\sqrt{A}\left(L_{c}-L_{0}-L_{p}\right)\right)}{\sqrt{A}\left(1+e^{L_{p} \sqrt{A}}\right)} B P ; \\
& C_{4}=-\frac{e^{-L_{p} \sqrt{A}}-\sqrt{A} e^{-L_{p} \sqrt{A} / 2}\left(L_{c}-L_{0}-L_{p}\right)}{\sqrt{A}\left(e^{-L_{p} \sqrt{A} / 2}+e^{L_{p} \sqrt{A} / 2}\right)} B P .
\end{aligned}
$$

Combining (24) and (19), the shear stress at the interface between the CFRP and the adhesive layer $\tau(x)$ can be expressed as the following:

$$
\begin{aligned}
& \tau(x) \\
& = \begin{cases}-t_{p} B P\left(\frac{e^{L_{p} \sqrt{A} / 2}-L_{0} \sqrt{A} e^{L_{p} \sqrt{A}}}{\left(1+e^{L_{p} \sqrt{A}}\right)} e^{-\sqrt{A} x}+\frac{e^{L_{p} \sqrt{A} / 2}+L_{0} \sqrt{A}}{\left(1+e^{L_{p} \sqrt{A}}\right)} e^{\sqrt{A} x}+1\right) & \left(0 \leq x<\frac{L_{p}}{2}\right) \\
t_{p} B P \frac{e^{L_{p} \sqrt{A}}\left(e^{L_{p} \sqrt{A} / 2}-\left(L_{c}-L_{0}-L_{p}\right) \sqrt{A}\right)}{\left(1+e^{L_{p} \sqrt{A}}\right)} e^{-\sqrt{A} x}+t_{p} B P\left(\frac{e^{L_{p} \sqrt{A}}-\sqrt{A} e^{-L_{p} \sqrt{A} / 2}\left(L_{c}-L_{0}-L_{p}\right)}{\left(e^{-L_{p} \sqrt{A} / 2}+e^{L_{p} \sqrt{A} / 2}\right)}-1\right) & \left(\frac{L_{p}}{2} \leq x<L_{p}\right) .\end{cases}
\end{aligned}
$$

2.3. Parametric Analysis. In this section, based on (25), selected parameters that affect shear stress as CFRP length and CFRP thickness are parametrically analyzed to provide a reference for the subsequent experiment design. Given the geometrical symmetry of the reinforced concrete beam, only one half of the structure is adopted for analysis. The mechanical model is illustrated in Figure 1.

2.3.1. Effect of the Length of CFRP Layer on Shear Stress. The values for material properties and geometrical dimension are shown Table 1. The same values are applicable for the experimental study to be discussed below. Considering the CFRP length of $0.1 \mathrm{~m}, 0.2 \mathrm{~m}$, and $0.35 \mathrm{~m}$, the shear stress distribution corresponding to the three different lengths of CFRP length was obtained from a calculation and is shown in Figure 3. For the different lengths of CFRP, the shear stress at the interface between the CFRP and the concrete beam was uniform except for the first $0.02 \mathrm{~m}$ length from the starting point. This result shows that an increase in CFRP length results in an obvious improvement in the stress concentration. It also indicates that the failure mode of the reinforced beam bonded with a longer CFRP layer is more likely to follow the shear failure mode than would a beam bonded with a shorter CFRP layer. The subsequent experimental observation supports the prediction, as will be shown in Section 3.

2.3.2. Effect of the Thickness of CFRP Layer on the Interfacial Shear Stress. Analogous to the previous section, for the CFRP thicknesses of $1 \mathrm{~mm}$ (single layer of CFRP) and $2 \mathrm{~mm}$ 
TABLE 1: Material properties for CFRP and concrete material and dimensions for the specimen.

\begin{tabular}{llc}
\hline The category & Material property & Values \\
\hline $\begin{array}{l}\text { Typical material } \\
\text { properties for CFRP, } \\
\text { concrete, and adhesive } \\
\text { layer }\end{array}$ & $\begin{array}{l}\text { Elastic modulus for CFRP } \\
\text { Elastic modulus for } \\
\text { concrete } \\
\text { Shear modulus for the } \\
\text { adhesive }\end{array}$ & $150 \mathrm{GPa}$ \\
& $\begin{array}{l}\text { The height of concrete } \\
\text { beam } \\
\text { The thickness for the } \\
\text { adhesive } \\
\text { The thickness for the } \\
\text { beometrical dimension } \\
\text { for the concrete } \\
\text { specimen }\end{array}$ & $0.89 \mathrm{GPa}$ \\
& $\begin{array}{l}\text { The moment of inertial for } \\
\text { concrete beam }\end{array}$ & $0.0005 \mathrm{~m}$ \\
& $8.33 e-6 \mathrm{~m}^{4}$ \\
\hline
\end{tabular}

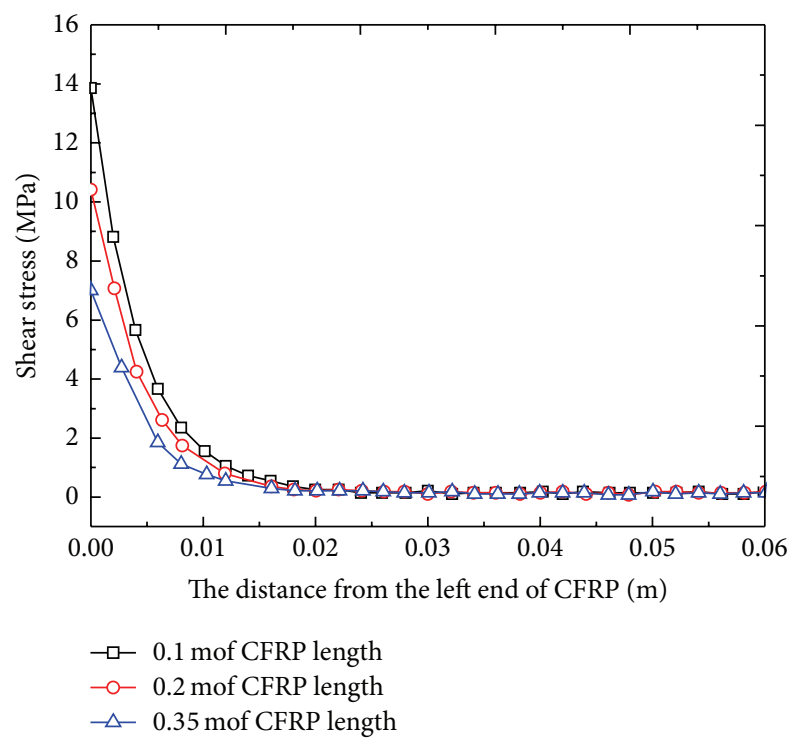

Figure 3: The plot of shear stress for various CFRP lengths against the distance from the left CFRP end.

(double layers of CFRP), the corresponding parameters were calculated based on the material properties as shown in Table 1 . The thicknesses of $1 \mathrm{~mm}$ and $2 \mathrm{~mm}$ were chosen to study the influence of CFRP thickness on the mode of failure of the CFRP-strengthened beam. The shear stress distribution for the two thicknesses was obtained as shown in Figure 4. It shows that as the CFRP thickness increases, the shear stress decreases, and the stress concentration at the end of the CFRP layer becomes less obvious. Alternatively, it indicates that, with a reduction in the CFRP thickness, the shear stress concentration at the end of the CFRP layer becomes more significant, thus, increasing the possibility of shear failure mode for a thinner layer of CFRP than for a thicker layer.

\subsection{Determination for the Ultimate Load}

2.4.1. The Fracture Criterion. In this study, the ultimate load is defined as the magnitude of load at which the initial

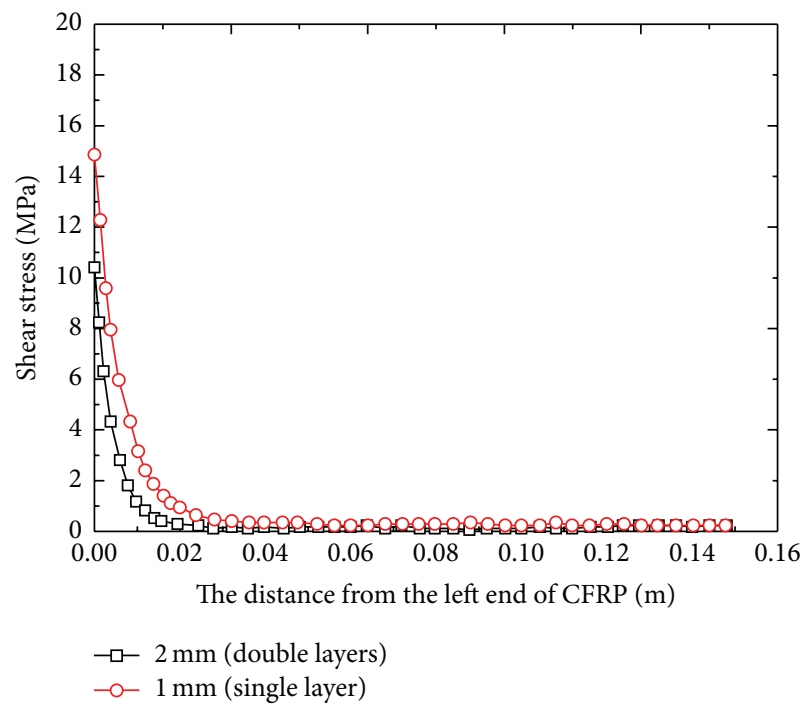

FIgURE 4: The plot of shear stress for various CFRP thicknesses against the distance from CFRP end.

crack (notch) located at the middle of the beam starts to propagate. There are commonly three fracture criteria in linear elastic fracture mechanics as $K$ (stress intensity factor), $J$ integral, and strain energy release rate (SERR), which are used to determine whether and when crack propagates [17]. The criteria for both $K$ and SERR are for linearly elastic materials, while $J$ integral criterion is for plastic materials. As illustrated in Figure 1, since the initial notch is predefined at the middle of the beam, the failure mode for the geometrical configuration of the concrete beam is responsible for the opening mode (mode I) of failure. In addition, the concrete behaves in brittle manner and is considered as an elastic material $[1,8,10,18]$. Consequently, $K$ criterion is chosen as the fracture criterion to define the ultimate load, as shown in

$$
K_{I} \geq K_{I C}
$$

Equation (26) states that the crack will grow when the stress intensity factor of the given concrete beam structure $K_{I}$ is greater than or equal to the critical value $K_{I C}$. The quantity $K_{I C}$ is the critical stress intensity factor which is considered to be a material property independent of the applied load and the geometric configuration of the beam.

2.4.2. The Calculation for Stress Intensity Factor. For the three-point bending concrete beam, the expression calculating the value for $K_{I}$ follows (27), wherein $P$ is the load applied at the mid-span of the concrete beam, $S$ is the span distance between two supports of the concrete beam, $t$ is the thickness of the concrete beam, $a$ is the notch depth (also crack depth, shown in Figure 1), and the expression for $F(\alpha)$ can follow (28), as follows:

$$
\begin{aligned}
K_{I} & =\frac{3 S P}{2 t W^{2}} \sqrt{\pi a} F(\alpha), \\
F(\alpha) & =\frac{1.99-\alpha(1-\alpha)\left(2.15-3.93 \alpha+2.7 \alpha^{2}\right)}{\sqrt{\pi}(1+2 \alpha)(1-\alpha)^{3 / 2}}, \\
\text { where } \alpha & =\frac{a}{w} .
\end{aligned}
$$


TABLE 2: The specific proportion for component material.

\begin{tabular}{|c|c|c|c|c|c|c|}
\hline Material & Cement & Coarse aggregate & Fine aggregate & Water & Concrete admixture & Fly-ash \\
\hline Weight per concrete cubic meter $(\mathrm{kg})$ & 300 & 615 & 1210 & 185 & 6.60 & 95 \\
\hline Mass ratio & 1.000 & 2.050 & 4.033 & 0.617 & 0.022 & 0.317 \\
\hline
\end{tabular}

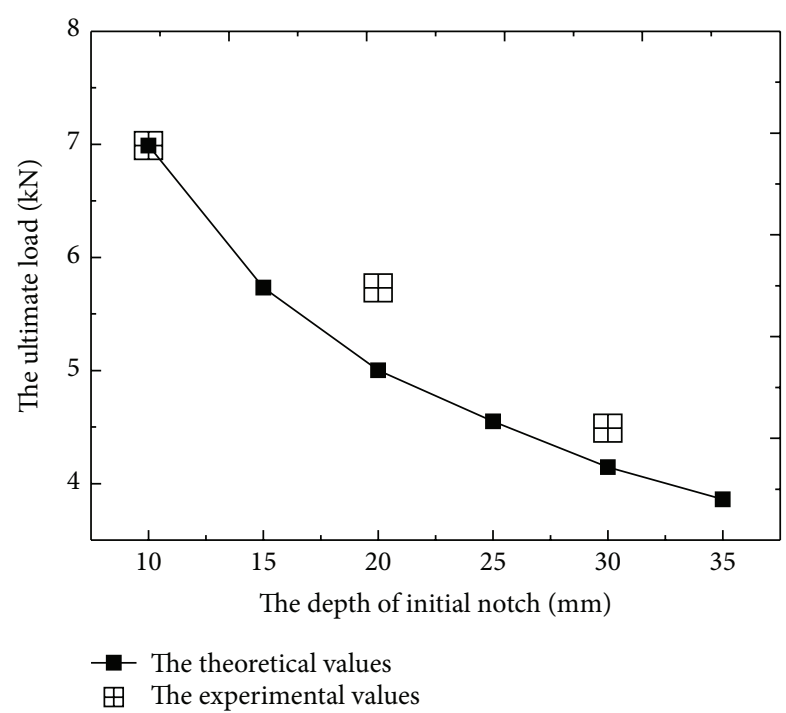

FIGURE 5: The comparison of the ultimate load between theoretical calculation and experimental measurement.

2.4.3. Verification for the Ultimate Load. In order to assure the accuracy in the calculation of the ultimate load for the concrete beam, the ultimate loads corresponding to different depths of the initial notch were compared between a theoretical calculation and the experimental measurement. The critical stress intensity factor in the present work was taken as $K_{I C}=0.62 \mathrm{MPa} \cdot \mathrm{m}^{1 / 2}[19]$. Substituting the geometric dimensions and the lengths of initial notch in (27), the ultimate load capacities were calculated and are shown as the cross air dots in Figure 5 for $10 \mathrm{~mm}, 20 \mathrm{~mm}$, and $30 \mathrm{~mm}$, respectively. Additionally, the solid dots represent the values for the ultimate load capacities from the theoretical derivation. It can be seen that they are in good agreement with each other, especially for the case of $10 \mathrm{~mm}$, which indicates the accuracy of the experiment.

\section{Experiment Procedures}

3.1. Materials Preparation. Concrete was used for the fabrication of the concrete specimens, with the specific composition for each constituent material as summarized in Table 2. The strength class for cement was $42.5 \mathrm{R}$, which belonged to an ordinary Portland cement and was manufactured by Chongqing Tenhui-Diwei Limited Corporation, China. The mud contents for the fine and coarse aggregates were less than $3.0 \%$ and less than $5.0 \%$, respectively. A pumping admixture, manufactured by Chongqing Chuanqing Chemical Plant, was used in the concrete mix design to make a concrete block
TABLE 3: The ultimate strength variation with curing days.

\begin{tabular}{lc}
\hline Curing days & Compressive strength (MPa) \\
\hline 3 & 23.4 \\
7 & 29.9 \\
28 & 41.4 \\
\hline
\end{tabular}

with a higher compressive strength and to achieve a better pumping performance for concrete. A slump test was firstly performed on the fresh concrete mixed according to the mix proportion shown in Table 2 to investigate the workability of the concrete, thus, ensuring a successful casting of the concrete beams.

CFRP is normally manufactured in the shape of a plate, which is mainly attached to the surface of a flexural member in structures to resist the tension along the fiber direction. CFRP used in this study was produced by Taiwan Zhongyi Company. The tensile strength and the ductility for CFRP were $4640 \mathrm{MPa}$ and $1.7 \%$, respectively. The elastic modulus for CFRP along the longitudinal direction was $165 \mathrm{GPa}$ and Poisson's ratio was 0.25 .

The bonding performance of a structural adhesive plays a significant role in the overall mechanical behavior of a CFRP-strengthened concrete beam. It acts as a medium to solidify carbon fibers into a bundle as the shape of a sheet, to transfer shear stress from the interface, and to resist the tension from the notched concrete beam. The structural adhesives used in the experiment were of three types as the surface repair adhesive (type: YZJ-CZ), assembly glue (type: YZJ-CD), and impregnating adhesive (type: YZJ-CQ). All the adhesive products used in this study were produced by Wuhan-Yangtze-River Limited Company (Table 3).

\subsection{Manufacturing of the Concrete Specimen}

3.2.1. Fabrication of the Notched Concrete Specimen. The initial notch was fabricated during manufacturing the concrete beam specimens. The notches were located at the middle part of the concrete beams as shown in Figure 1. According to the literature [20], they were cut at the middle span of the concrete beams with a steel saw after hardening of concrete. The notches in the different specimens had various widths due to errors during the cutting process. Thus, when all of the initial notches in concrete specimens were processed completely, they were uniformly extended to rectangular ones measuring $3 \mathrm{~mm}$ in width. According to the recommendation of Japanese Society of Civil Engineering, the dimensions of the concrete samples were $0.1 \mathrm{~m} \times 0.1 \mathrm{~m} \times 0.4 \mathrm{~m}$ (refer to Figure 1). To eliminate the randomness of the concrete material, each group of test specimens contained three 
replicates of concrete beams assigned as numbers 1, 2, and 3, respectively. Each concrete beam was subjected to a load test. The production process for each beam can be summarized as follows: (1) casting concrete into a mold; (2) vibrating it for 30 seconds, leveling and finishing the upper surface, and maintaining it in the mold for one day; (3) demolding and cutting notches on the concrete beams; and (4) maintaining it at a room temperature of $20 \pm 3^{\circ} \mathrm{C}$ for 28 days.

3.2.2. Procedures for Bonding the CFRP Layer on the Concrete Beam. The procedure for bonding CFRP at the bottom of a concrete beam plays an important role in reinforcing structures since the reinforcement efficiency of the CFRP on the concrete beam, whose middle section is embedded with an initial notch, is governed mainly by the adhesive layer that transmits shear stress load from the concrete material to CFRP, thus preventing further crack development. To obtain a better bonding performance, the following procedures were adopted: (1) polishing the surface of the concrete beams with an abrasive cloth, cleaning the debris in the notches, and washing the samples with acetone solvent to remove oil stains; (2) gluing the surface repair adhesive on the surface of the concrete samples with flaws to level them; (3) brushing the resulting surface of concrete after solidification of the surface repair adhesive; (4) brushing the impregnating adhesive on the two surfaces of the CFRP that had been cut, sticking this adhesive on the surface of the concrete, and scraping the bubbles and unnecessary impregnating adhesive with a scraping tool; (5) repeating steps (3) and (4) to bond the second layer of the CFRP on the beams with two layers of CFRP; and (6) repeating steps (3) and (4) to bond the Ushaped caps on some of the beam specimens.

3.3. Experiment Design. In the experiment, the factors affecting the mechanisms of CFRP-reinforced concrete beams were investigated in terms of failure behavior (ultimate load and final failure mode) of the reinforced structures subjected to three-point bending load. In the experiment, the plain concrete beam with an initial notch was used to be reinforced by CFRP. No steel reinforcement was used in any beams. A number of notches with different depths were first prepared on the tensile surface of the concrete beam before reinforcement. Then, CFRPs of different lengths were bonded to the tensile surface comprising an initial notch. The experimental design can be grouped into four cases as case 1: to determine the effect of the CFRP length on the failure modes and on the ultimate load capacity when the initial crack is identical; case 2: to determine the effect of the notch depth on the failure modes and on the ultimate load capacity when the length of CFRP remains constant; case 3: to determine the effect of CFRP thickness on the failure modes and on the ultimate load capacity; and case 4: to determine the effect of bonding methods such as Ushaped caps wrapped at the plate end on the failure modes and the ultimate load capacity. Table 4 lists the details of the test specimens in the experiment. In total, 54 concrete specimens were tested in the experiment and were observed for the ultimate load and the final failure behavior.
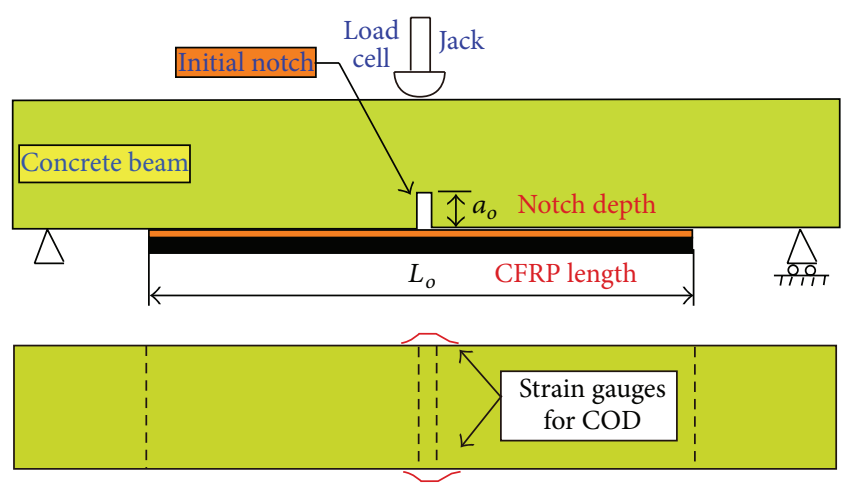

FIGURE 6: The sketch for test setup.

3.4. Test Setup. As a continuation to our previous research [21], the purpose in the present experimental work was to qualitatively investigate the failure behaviors of CFRPstrengthened concrete beams and to quantitatively analyze how the length of CFRP, the thickness of CFRP, and the methods of bonding affect the ultimate load capacity and the final failure mode of the CFRP-strengthened concrete beams. Meanwhile, although the crack opening displacement (COD) for the initial notch was not adopted in the present analysis, to assure the integrity of experiment, COD was also measured for the test specimens. A detailed discussion on COD can be found in [21]. As illustrated in Figure 6, the middle section of the concrete beam was subjected to a jack pressure and the load was applied at the mid-length of the concrete beam. The reaction was provided by the two roller supports near the two ends of each specimen. The values for the ultimate load for the CFRP-reinforced concrete beam were logged at an instrument. Two strain gauges were attached close to the root of the initial notch on both sides of the specimen for measuring the average COD for the notch under the applied loading.

\section{Results and Discussions}

4.1. Failure Modes. Figure 7 shows four different failure modes of the CFRP-strengthened concrete beams as observed in the experiment. The four failure modes from Figures 7(a)7(d) are termed as brittle fracture, shear failure I, shear failure II, and delamination failure, respectively. As shown in Figure 7, the brittle fracture mode refers only to the case of an unreinforced concrete beam. The fracture was caused by the propagation of the main crack located at the middle of the concrete due to the tensile stress concentration at the tip of the initial notch and to the subsequent extension of the crack as the applied load increased. From the experimental observation, the fracture surface for the brittle failure was uneven that resembled a skew path of crack propagation.

Figure 7(b) shows one of the shear failure modes observed in the experiment, which is defined as shear failure I mode in this paper. The letter "I" just signifies one kind of failure mode in order to distinguish it from the second shear failure mode (II) in the experiment, which is dramatically different from the modes I, II, and III in the classical fracture mechanics. The crack development process 
TABLE 4: The details for the tested concrete specimens.

\begin{tabular}{|c|c|c|c|c|c|}
\hline Objective & Type & No.* & Description & $\begin{array}{l}\text { CFRP length } \\
(\mathrm{mm})\end{array}$ & $\begin{array}{l}\text { Notch } \\
\text { depth } \\
(\mathrm{mm})\end{array}$ \\
\hline \multirow{12}{*}{ The effect of CFRP length } & \multirow{4}{*}{ Group I } & $10-000$ & Without CFRP & 0 & \multirow{4}{*}{10} \\
\hline & & $10-100$ & Single-layer CFRP & 100 & \\
\hline & & $10-200$ & Single-layer CFRP & 200 & \\
\hline & & $10-350$ & Single-layer CFRP & 350 & \\
\hline & \multirow{4}{*}{ Group II } & $20-000$ & Without CFRP & 0 & \multirow{4}{*}{20} \\
\hline & & $20-100$ & Single-layer CFRP & 100 & \\
\hline & & $20-200$ & Single-layer CFRP & 200 & \\
\hline & & $20-350$ & Single-layer CFRP & 350 & \\
\hline & \multirow{4}{*}{ Group III } & $30-000$ & Without CFRP & 0 & \multirow{4}{*}{30} \\
\hline & & $30-100$ & Single-layer CFRP & 100 & \\
\hline & & $30-200$ & Single-layer CFRP & 200 & \\
\hline & & $30-350$ & Single-layer CFRP & 350 & \\
\hline \multirow{3}{*}{ The effect of notch depth } & \multirow{3}{*}{ (Group IV) } & $10-000$ & Without CFRP & 0 & \multirow{3}{*}{$\begin{array}{l}10 \\
20 \\
30\end{array}$} \\
\hline & & $20-200$ & Single-layer CFRP & \multirow{2}{*}{200} & \\
\hline & & $30-200$ & Single-layer CFRP & & \\
\hline \multirow{12}{*}{$\begin{array}{l}\text { The effect of CFRP } \\
\text { thickness and bonding } \\
\text { method }\end{array}$} & \multirow{4}{*}{ Group V } & $20-000$ & Without CFRP & 0 & \multirow{12}{*}{20} \\
\hline & & $20-100$ & Single-layer CFRP & \multirow{3}{*}{100} & \\
\hline & & $20-100 s$ & Two-layer CFRP & & \\
\hline & & $20-100 b$ & $\begin{array}{l}\text { Single-layer CFRP and } \\
\text { using U-shaped cap }\end{array}$ & & \\
\hline & \multirow{4}{*}{ Group VI } & $20-000$ & Without CFRP & 0 & \\
\hline & & $20-200$ & Single-layer CFRP & & \\
\hline & & $20-200 s$ & Two-layer CFRP & & \\
\hline & & $20-200 b$ & $\begin{array}{l}\text { Single-layer CFRP and } \\
\text { using U-shaped cap }\end{array}$ & 200 & \\
\hline & & $20-000$ & Without CFRP & 0 & \\
\hline & Group VII & $20-350$ & Single-layer CFRP & & \\
\hline & Gove vit & $20-350 s$ & Two-layer CFRP & & \\
\hline & & $20-350 b$ & $\begin{array}{l}\text { Single-layer CFRP and } \\
\text { using U-shaped cap }\end{array}$ & 350 & \\
\hline
\end{tabular}

${ }^{*}$ Explanation for No. A-B (the 3rd column): A is for the length of the initial notch, B for the bonded CFRP length, s for two layers of CFRP, and b for U-shaped cap used for one single layer of CFRP.

for shear failure I mode is depicted in Figure 8. For the concrete beams reinforced with CFRP, a number of minor cracks were generated because of the stress concentration at the tip of the initial notch (Figure 8(a)) at the beginning of the applied load. During the loading process, minor cracks continued to develop, with some of them coalescing to form macrocracks (Figure $8(\mathrm{~b})$ ). As the load $P$ increased, the CFRP bonded at the tensile surface of the concrete beam started to prevent the macrocracks from propagating. This prevention, consequently, reduced the stress concentration at the tip of the initial notch. However, the shear stress at the interface between the concrete beam and the CFRP increased successively because of the continuous increase in the load on the concrete beam (Figure 8(c)). Furthermore, smeared cracks were generated on the interface between concrete and CFRP. These cracks were formed at a 45-degree angle along the horizontal axis of the beam. The macrocracks (smeared cracks) developed rapidly towards the direction of the 45degree angle until the beam was fractured (Figure 8(d)). Note that the smeared cracks did not intersect the main crack but maintained a certain distance with them (Figure 8(d)). The resulting crack surface was more even than for the brittle failure mode.

Figure 7(c) shows the other shear failure mode in the experiment, termed as mode II. Figure 9 shows a schematic of the gradual development for the shear failure II. The initiation of cracks for this failure mode was similar to that for shear failure I mode (Figures 9(a) and 9(b)). However, when the shear cracks developed at a 45-degree angle to the direction of the horizontal axis of the beam, CFRP peeled off slightly at a small length. This is attributed to (a) the relatively shorter length of CFRP layer for the specimens with 


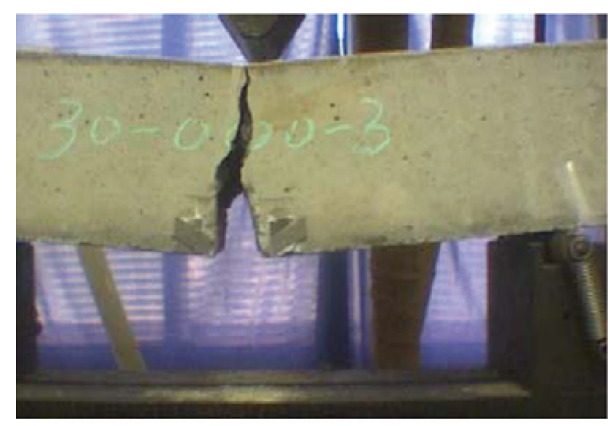

(a) Brittle fracture

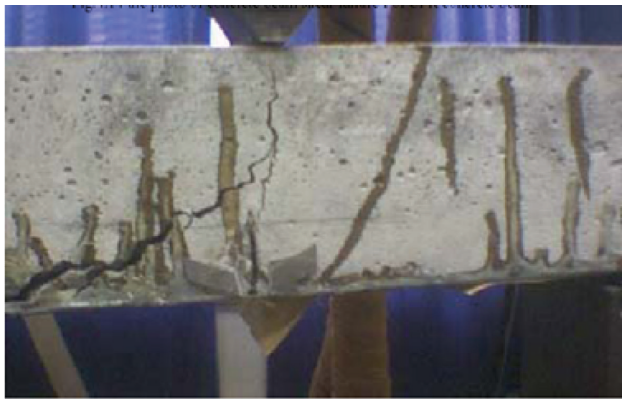

(c) Shear failure II

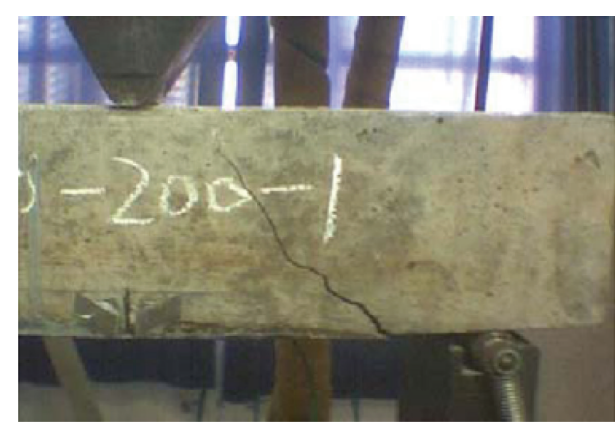

(b) Shear failure I

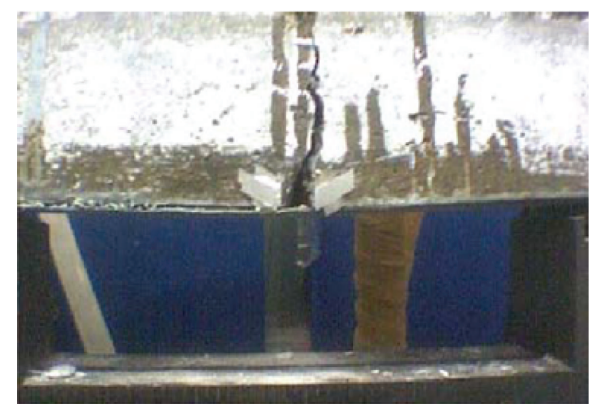

(d) Delamination failure

FIgURE 7: Final failure modes observed in experiment: (a) brittle fracture; (b) shear failure I; (c) shear failure mode II; (d) delamination failure.

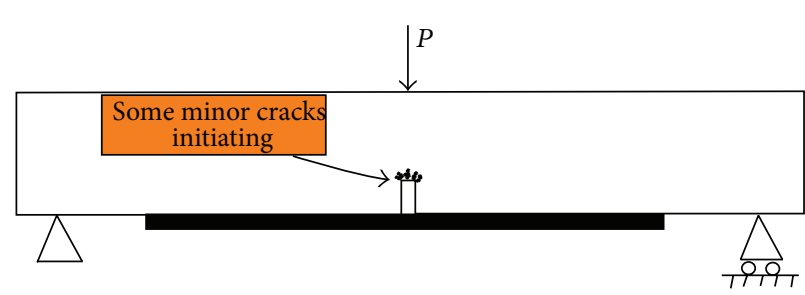

(a)

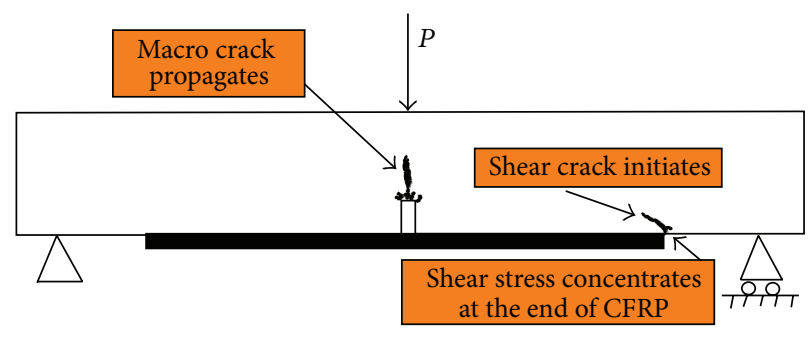

(c)

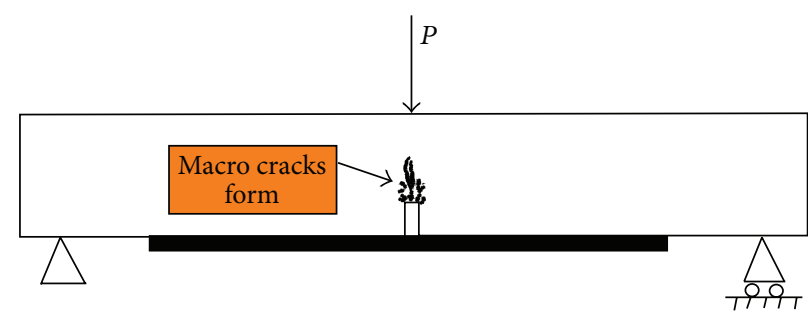

(b)

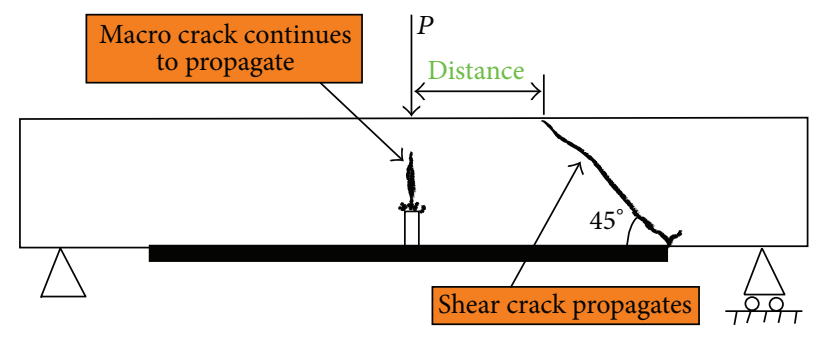

(d)

Figure 8: The sketch for the development of shear failure I mode.

this mode of failure and (b) the failure of the adhesive at the CFRP end (Figure 9(c)). At the same time, one smeared crack occurred at this site. Given that the newly created shear cracks were close to the mid-span of the concrete beam, they easily approached the initial main crack located at the midspan of the concrete beam, which resulted in a relatively large macrocrack that penetrated the concrete portion of the reinforced beam (Figure 9(d)). Given that both the bending moment and the tensile stress of the cross section of the crack were the largest, the macrocracks penetrated by the shear cracks and the initial main cracks propagated along the axis of the beam instead of along the path of the 45-degree angle. This phenomenon led to the failure of the reinforced beam. It should be noted that the essential difference between the shear I and II modes is the approaching of the two cracks for the shear II mode but not for the shear I mode. The possible 


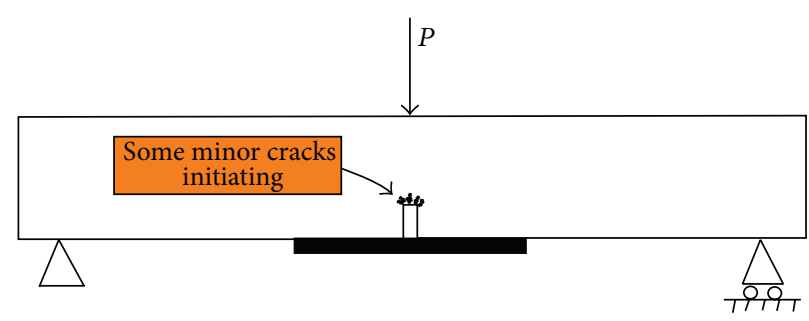

(a)

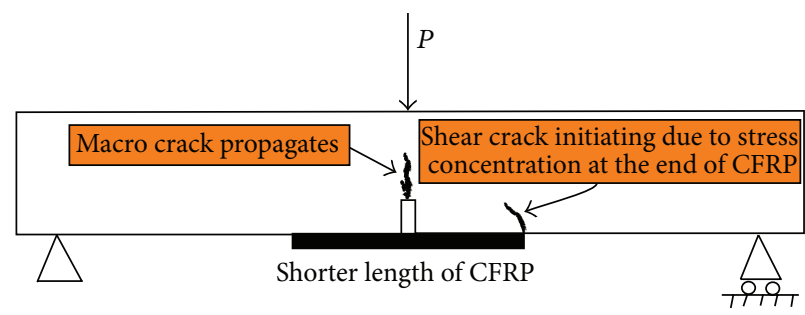

(c)

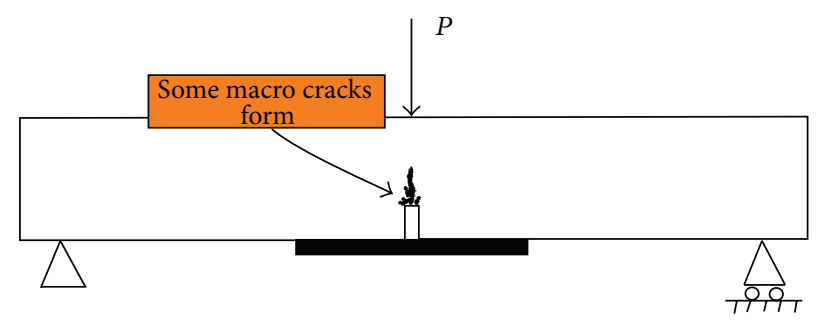

(b)

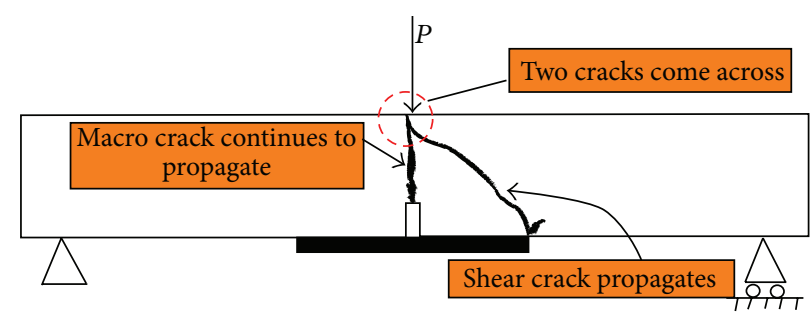

(d)

FIGURE 9: The sketch for the development of shear failure II mode.

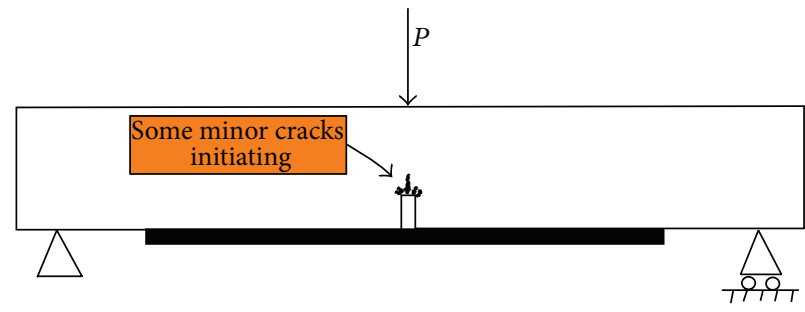

(a)

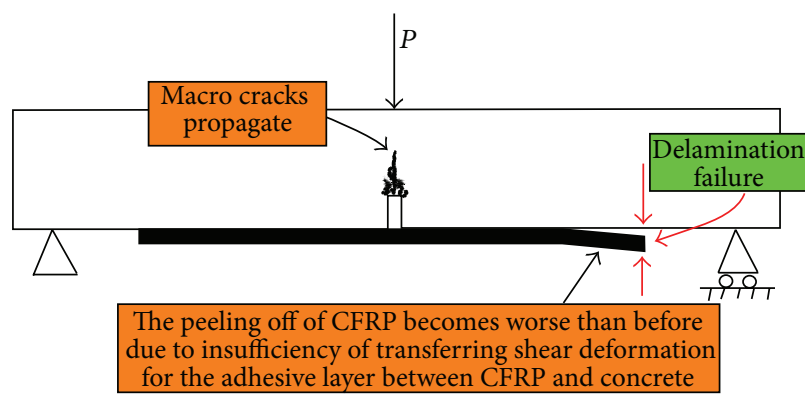

(c)

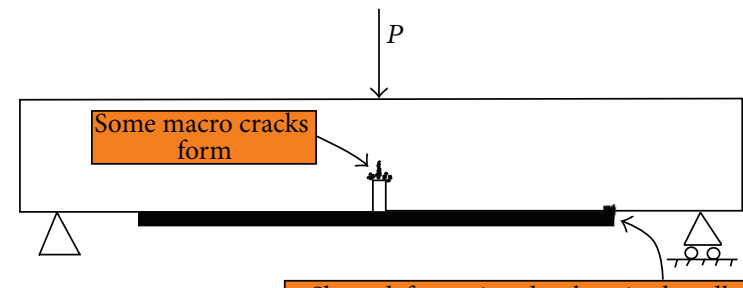

Shear deformation develops in the adhesive at the end of CFRP. Minor delamination failure (peeling off of CFRP at the site) occurs

(b)

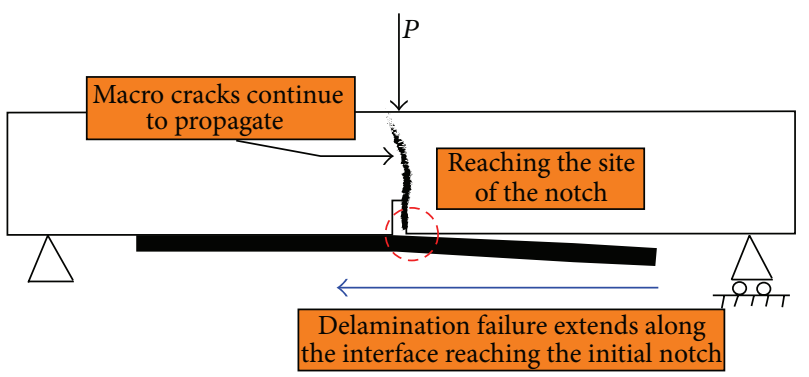

(d)

FIGURE 10: The sketch for the development of delamination failure mode.

reason for this could be the length of the CFRP layer bonded at the bottom of concrete beam. A shorter layer led to a larger stress concentration at CFRP end and created one smeared crack closer to the main crack unlike in the case of a longer CFRP layer.

Figure $7(d)$ shows the delamination failure mode. From the experimental observation, the delamination failure mode occurred for the case of the longest CFRP layer $(350 \mathrm{~mm})$ in this experiment. The reason for such failure mode could be explained as follows and can also be illustrated in Figure 10.
When the beam was loaded, the main crack located at the mid-span was extended because of the stress concentration at the tip (Figure 10(a)). Since the length of the bonded CFRP was significantly greater than in the other cases, it helped to relieve the shear stress concentration at CFRP end, thus causing relatively fewer shear cracks developed at the end (Figure 10(b)). However, as the load increased, propagation of the main crack was prevented because of the tensile stress developed in the CFRP layer. Incremental load was transferred to CFRP because of its high modulus. Meanwhile, 
TABLE 5: The statistics of failure modes for the tested specimens.

\begin{tabular}{|c|c|}
\hline The failure mode & Statistics for the corresponding specimens \\
\hline Brittle fracture & Totally 9 specimens, all for concrete beams without CFRP reinforcement \\
\hline Shear failure I & Totally 12 specimens: 3 for $10-100,2$ for $20-100,3$ for $30-100,2$ for $20-100 \mathrm{~b}$, and 2 for $30-350$ specimens \\
\hline Shear failure II & $\begin{array}{l}\text { Totally } 14 \text { specimens: } 1 \text { for } 20-100,3 \text { for } 10-200,3 \text { for } 20-200,3 \text { for } 30-200,2 \text { for } 20-100 \text { s, } 1 \text { for } 20-200 \text { s, and } 1 \text { for } \\
\text { 20-200b specimens }\end{array}$ \\
\hline Delamination failure & $\begin{array}{l}\text { Totally } 19 \text { specimens: } 3 \text { for } 10-350,3 \text { for } 20-350,1 \text { for } 30-350,1 \text { for } 20-100 \text { s, } 2 \text { for } 20-200 \text { s, } 3 \text { for } 20-350 \text { s, } 1 \text { for } \\
20-100 \text { b, } 2 \text { for } 20-200 \text { b, and } 3 \text { for } 20-350 \text { b specimens }\end{array}$ \\
\hline
\end{tabular}

Note. The description for failure modes can refer to the subsequent section, and the details for the specimen can refer to Table 4 .

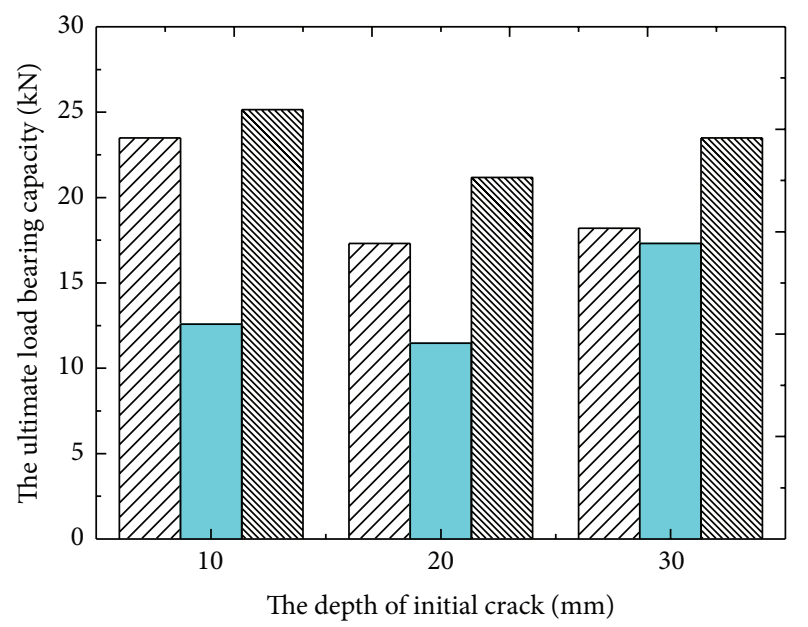

Shear failure I mode
Shear failure II mode
Debonding failure

FIGURE 11: The column representation for the ultimate load for reinforced concrete beam versus the depth of initial notch under various failure modes.

the adhesive layer between the concrete beam and the CFRP layer had to sustain more shear stress and also had to transfer a part of the incremental load by undergoing shear deformation. When the shear deformation exceeded the shear deformation capacity, the CFRP slid along the interface between the CFRP and the concrete beam. The main crack at the mid-span continued to propagate rapidly until the CFRP started to peel off the adjacent concrete material from the beam. The peeling off of CFRP at the end grew to ultimately cause the delamination failure (Figure 10(c)). Once delamination failure was initiated, which could significantly decrease the capability of concrete beam resisting the deformation, the phenomenon of peeling off of CFRP rapidly deteriorated until it reached the location of the initial notch (Figure 10(d)). It is worth mentioning that the delamination observed in the experiment (Figure 7(d)) differed slightly from the schematic shown in Figure 10(d) since the length of CFRP in Figure 7(d) happened to fall at the two supports of the beam. Nevertheless, a closer observation can find the similarity in essence between them.

Table 5 summarizes the final failure modes for the 54 test specimens in the experiment, and Figure 11 shows the variation in ultimate load capacity for the specimens with the initial depth of notch for different failure modes, shear failure I mode, shear failure II mode, and delamination failure, respectively. The presented statistics shows that nine specimens demonstrated the brittle fracture mode. They are the concrete beams not reinforced with CFRP. Twelve specimens demonstrated the shear failure I mode, 14 specimens demonstrated the shear failure II mode, and 19 specimens demonstrated the delamination failure. The specimens that exhibited the delamination failure comprised the largest group, accounting for $35 \%$ of the total. It also shows that, for concrete beams reinforced with CFRP, except for those beams with double layers of CFRP, 13 specimens failed in the delamination failure mode, but 26 specimens failed in the shear failure mode. These results strongly support the previous theoretical analysis, as discussed in Section 2.3.1. It can be explained as follows.

From (25), increasing CFRP length can significantly improve the shear stress $\tau(x)$, as seen in Figure 3 . The shear stress at the end of CFRP was increased from $7 \mathrm{MPa}$ to $14 \mathrm{MPa}$ when the length of the CFRP layer increased from $0.1 \mathrm{~m}$ to $0.35 \mathrm{~m}$ resulting in a much larger concentration of the shear stress at the end of CFRP. Equation (25) also indicates that the shear stress increases linearly with the applied load. Consequently, as the applied load increased at the mid-span of the beam, the shear stress concentration at the CFRP end further deteriorated. The concrete material at the end of the CFRP layer was subjected to significantly greater shear stress than at other locations till it exceeded the shear strength of concrete. As a result, the shear failure mode occurred for the beams with longer CFRP layer.

Table 5 also shows that the thinner the CFRP layer is, the more likely the failure is of the beam in the shear failure mode. In total, 3 out of 49 specimens reinforced with double layers of CFRP failed in the shear failure mode. This experimental observation supported the theoretical prediction as discussed in Section 2.3.2. The expression for the shear stress at the end of the CFRP layer (see (25)) explicitly includes a term, $t_{p}$, which stands for the thickness of CFRP. Figure 4 graphically illustrates the variation of shear stress at the CFRP end with an increase in the thickness of CFRP. The shear stress was increased from $10 \mathrm{MPa}$ to $15 \mathrm{MPa}$ when CFRP thickness decreased from $2 \mathrm{~mm}$ to $1 \mathrm{~mm}$. The thinner CFRP led to an increased concentration of the shear stress at the end of the CFRP layer. As the thickness of the CFRP layer increased, the shear stress was largely reduced, which was possibly caused 
TABLE 6: The ultimate load for concrete beams.

\begin{tabular}{|c|c|c|c|c|c|c|}
\hline $\begin{array}{l}\text { Number of } \\
\text { specimen }\end{array}$ & $\begin{array}{c}\text { Ultimate load } \\
(\mathrm{N})\end{array}$ & $\begin{array}{c}\text { Number of } \\
\text { specimen }\end{array}$ & $\begin{array}{l}\text { Ultimate load } \\
(\mathrm{N})\end{array}$ & $\begin{array}{c}\text { Number of } \\
\text { specimen }\end{array}$ & $\begin{array}{c}\text { Ultimate load } \\
(\mathrm{N})\end{array}$ & $\begin{array}{c}\text { Average load } \\
(\mathrm{N})\end{array}$ \\
\hline $10-000-1$ & 6700 & $10-000-2$ & 6850 & $10-000-3$ & 7250 & 6933.3 \\
\hline $10-100-1$ & 12064 & $10-100-2$ & 13085 & $10-100-3$ & 12574 & 12574.3 \\
\hline $10-200-1$ & 21636 & $10-200-2$ & 25400 & $10-200-3$ & 23034 & 23356.7 \\
\hline $10-350-1$ & 27179 & $10-350-1$ & 20983 & $10-350-3$ & 26966 & 25042.7 \\
\hline $20-000-1$ & 5527 & $20-000-2$ & 6725 & $20-000-3$ & 5005 & 5752.3 \\
\hline $20-100-1$ & 12002 & $20-100-2$ & 10975 & $20-100-3$ & 12090 & 11689 \\
\hline $20-200-1$ & 20021 & $20-200-2$ & 21020 & $20-200-3$ & 16787 & 19276 \\
\hline $20-350-1$ & 21280 & $20-350-2$ & 20674 & $20-350-3$ & 21376 & 21110 \\
\hline $20-100 s-1$ & 12632 & $20-100 s-2$ & 11465 & $20-100 s-3$ & 13935 & 12677.3 \\
\hline $20-200 s-1$ & 20574 & $20-200 s-2$ & 16679 & $20-200 s-3$ & 20473 & 19242 \\
\hline $20-350 s-1$ & 21285 & $20-350 s-2$ & 27275 & $20-350 s-3$ & 21365 & 23308.3 \\
\hline 20-100b-1 & 10517 & $20-100 b-2$ & 11120 & $20-100 b-3$ & 11789 & 11142 \\
\hline 20-200b-1 & 26059 & $20-200 b-2$ & 23680 & $20-200 b-3$ & 18530 & 22756.3 \\
\hline $20-350 b-1$ & 20169 & $20-350 b-2$ & 25114 & $20-350 b-3$ & 23996 & 23093 \\
\hline $30-000-1$ & 4714 & $30-000-2$ & 4564 & $30-000-3$ & 4425 & 4567.7 \\
\hline $30-100-1$ & 10696 & $30-100-2$ & 10382 & $30-100-3$ & 10064 & 10380.7 \\
\hline $30-200-1$ & 18051 & $30-200-2$ & 18492 & $30-200-3$ & 17875 & 18139.3 \\
\hline $30-350-1$ & 31214 & $30-350-2$ & 24210 & $30-350-3$ & 23496 & 26306.7 \\
\hline
\end{tabular}

by the shift of shear stress from the CFRP closet concrete side to the outer bottom of CFRP along the thickness direction of CFRP.

In regard to the shear failure modes I and II, the theoretical expression presented in this paper does not have the capability to predict the direction of crack propagation once it extends. This is one of the motivations in this paper to discuss the failure mechanism in the viewpoint of theory. However, as seen from the experimental observation, the shear cracks generated in the beams with the relatively shorter length of CFRP more easily penetrated the main crack located at the mid-span of the beam when compared to the shear cracks generated in the same beam types but with longer CFRP layers. This condition results in shear failure mode II. Figure 11 shows the relationship between the failure modes of the beams and their ultimate load capacities. For the same depth of the initial crack, the ultimate load capacity of the specimens in the delamination failure mode was the largest, followed by those in the shear failure I mode and subsequently the shear failure II mode. Delamination failure corresponded to the largest ultimate load capacity because of the least shear stress concentration. Given that the shear cracks run through the initial cracks after development, shear failure II has corresponded to the least ultimate load capacity.

4.2. Effect of the Length of CFRP and the Depth of Notch on the Ultimate Load Capacity of the Reinforced Beams. Table 6 lists the ultimate load capacities for the concrete beams in the experiment. The first, third, and fifth columns in Table 6 represent the three replicates of a particular type of concrete beam in the experiment; that is, "10-000" corresponds to three beams, marked as 10-000-1, 10-000-2, and 10-000-3, respectively. The last column is for the average value for the three concrete beams. Comparing with the theoretical derivation discussed in Section 2.4, the method for calculating the ultimate load for the concrete beam showed a good agreement with the experimental measurement (Figure 5). However, for the reinforced concrete beams, a detailed analysis requires a combination with finite element method [21-23]. Equations ((26)-(28)) aim especially for the case in which the stress intensity factor can be explicitly calculated. However, for the concrete beams reinforced with CFRP, (26)(28) are not in relation with the length and the thickness of the CFRP layer. In combination with the previous works [21-23], (26)-(28) can work very well in calculating the ultimate load capacity for any CFRP-reinforced concrete beams.

Figure 12 shows the effects of the length of CFRP and the initial notch depth on the ultimate load capacity of the CFRP-reinforced beams. Figure 12(a) presents the values of the ultimate bearing capacity of the unreinforced concrete beam. The experimental results showed that a longer initial notch corresponds to a smaller ultimate load capacity of the concrete beam. As the notch depth increased, the fracture toughness of the crack approached the critical value of the concrete beam, and hence the bearing capacity was decreased. Figure 12(a) shows that when the depth of the initial notch increased to $30 \mathrm{~mm}$, the ultimate load capacity of the concrete beam decreased from $7.25 \mathrm{KN}$ to $4.564 \mathrm{KN}$, which represents a decrease by $37 \%$.

However, with an increase in the length of the CFRP layer, the ultimate bearing capacity of the CFRP-reinforced beam was increased (Figures 12(b), 12(c), and 12(d)). The greatest ultimate load capacity of the CFRP-reinforced beam was seven times greater than that of the otherwise identical 


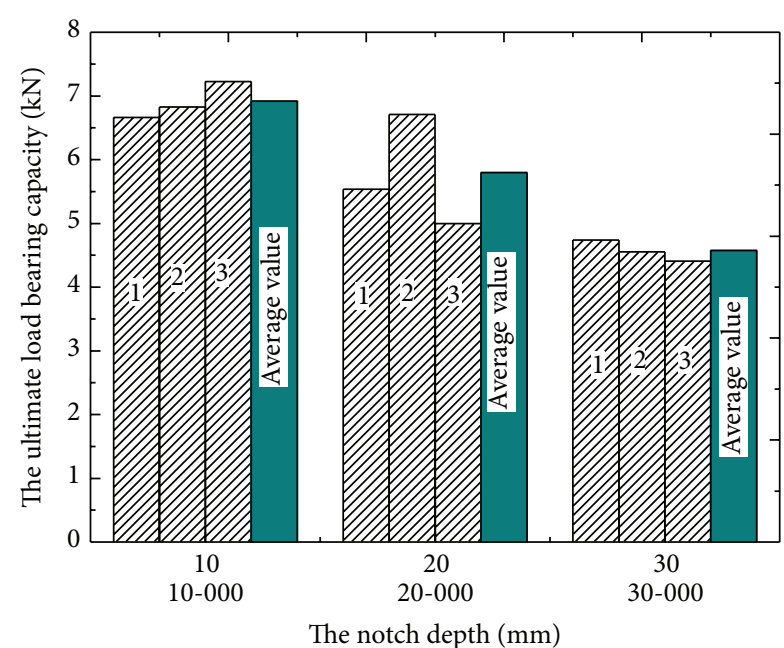

पIIS Value for each specimen

$\square$ Average value

(a)

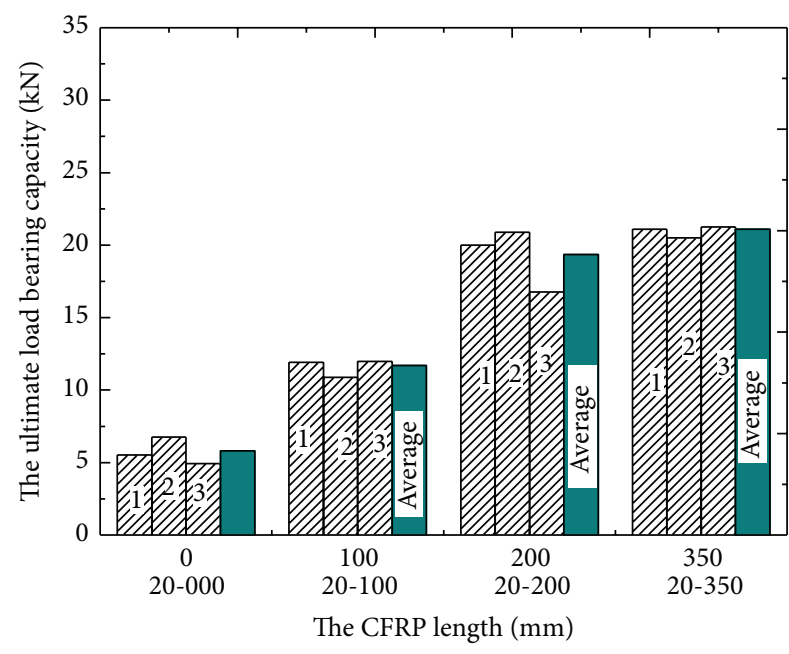

שIIA Value for each specimen

$\square$ Average value

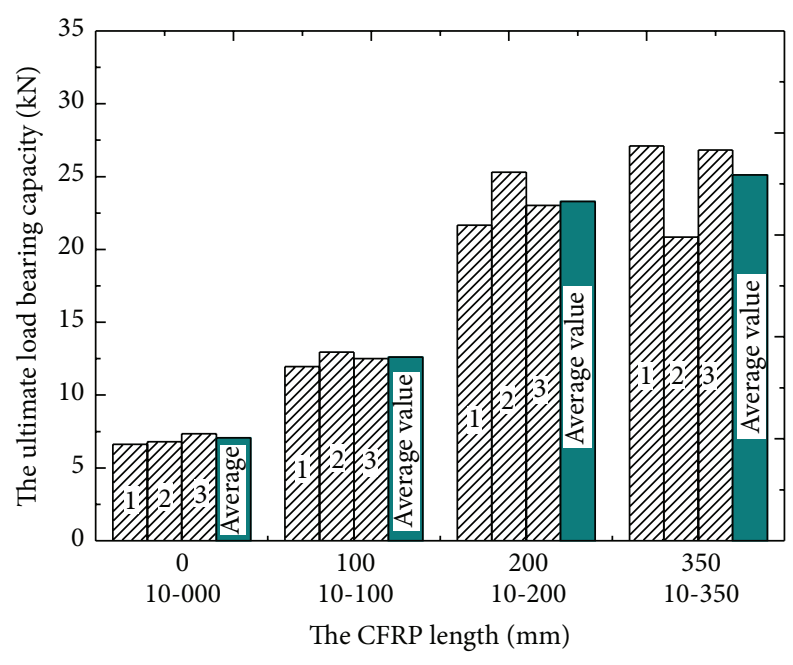

IIIS Value for each specimen Average value

(b)

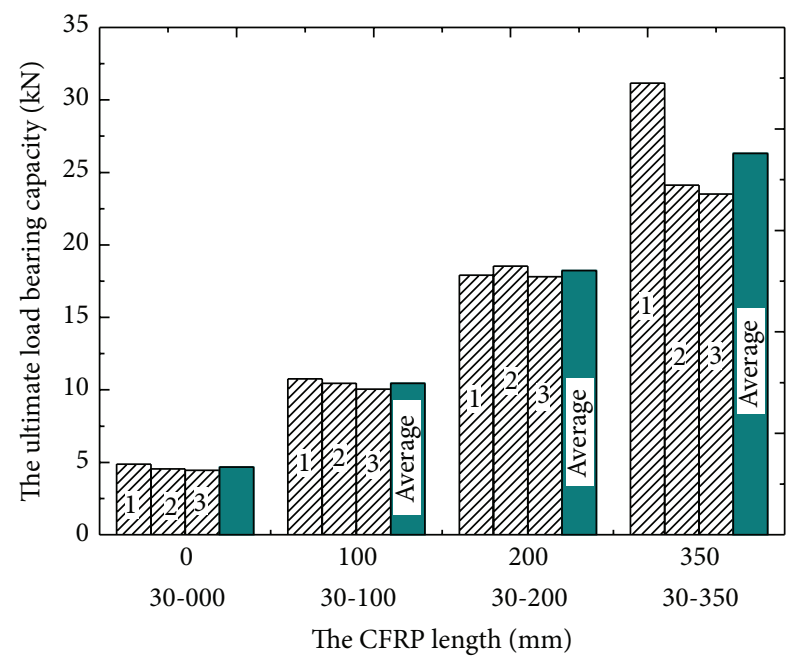

पIIS Value for each specimen

$\square$ Average value

(c)

(d)

FIGURE 12: (a) The effects of initial notch depth on the ultimate bearing capacity of concrete beam without CFRP strengthened; (b) the effect of CFRP length on the ultimate load bearing capacity of reinforced concrete beam for the notch depth of $10 \mathrm{~mm}$; (c) the effect of CFRP length on the ultimate load bearing capacity of reinforced concrete beam for the notch depth of $20 \mathrm{~mm}$; (d) the effect of CFRP length on the ultimate load bearing capacity of reinforced concrete beam for the notch depth of $30 \mathrm{~mm}$.

unreinforced beam (as shown in Figure 12(d)). However, the bearing capacity of the reinforced beam did not increase linearly with an increase in the length of the CFRP layer. The experiment results indicated that the bearing capacities of the reinforced beam did not increase further when the length of the CFRP layer was increased in excess of $200 \mathrm{~mm}$. This observation reveals the maximum reinforcement effect of the CFRP-reinforced concrete beam structure.

However, the effectiveness of the additional length of the CFRP layer was seen to increase with an increase in the initial notch depth. Figure 12(d) shows that the bearing capacity of the beam when the carbon fiber plate was $350 \mathrm{~mm}$ long increased more significantly than that when the carbon fiber plate is $200 \mathrm{~mm}$ long. This finding indicates that when the depth of the initial crack is small, its influence on the bearing capacity of the reinforced beam is not obvious. When CFRP length increases, its influence becomes obvious. An increase in the depth of the initial notch reduced the overall stiffness of the concrete beam. However, the bonded CFRP not only compensated for the structural flaw of the cracks but also increased the stiffness of the structure. When CFRP layer was longer, its role in reinforcement became significant. 


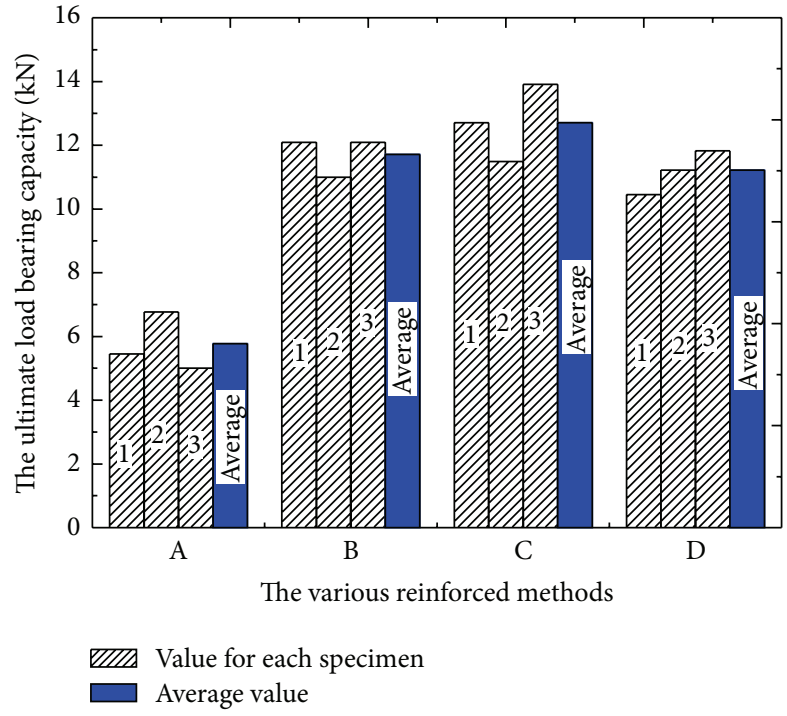

(a)

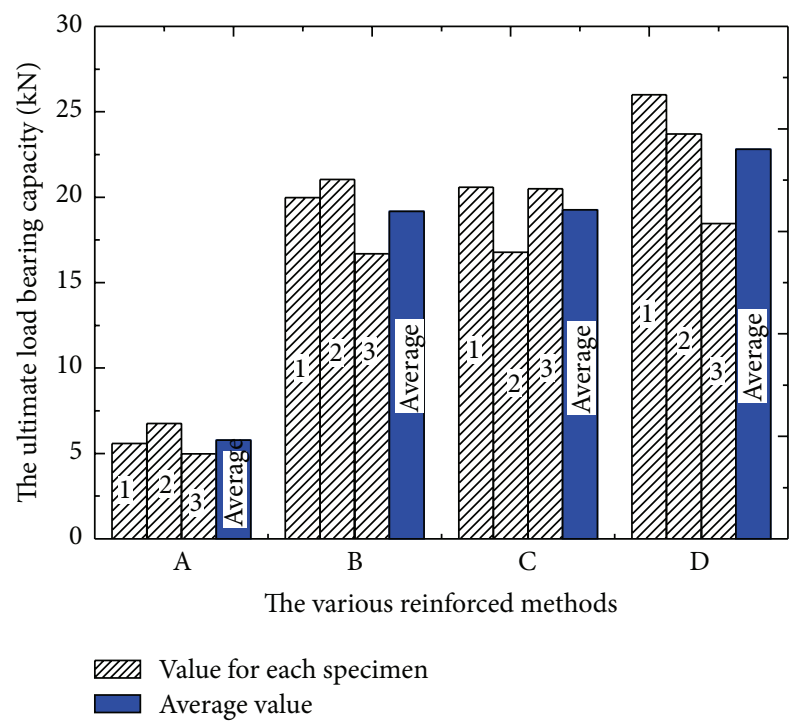

(b)

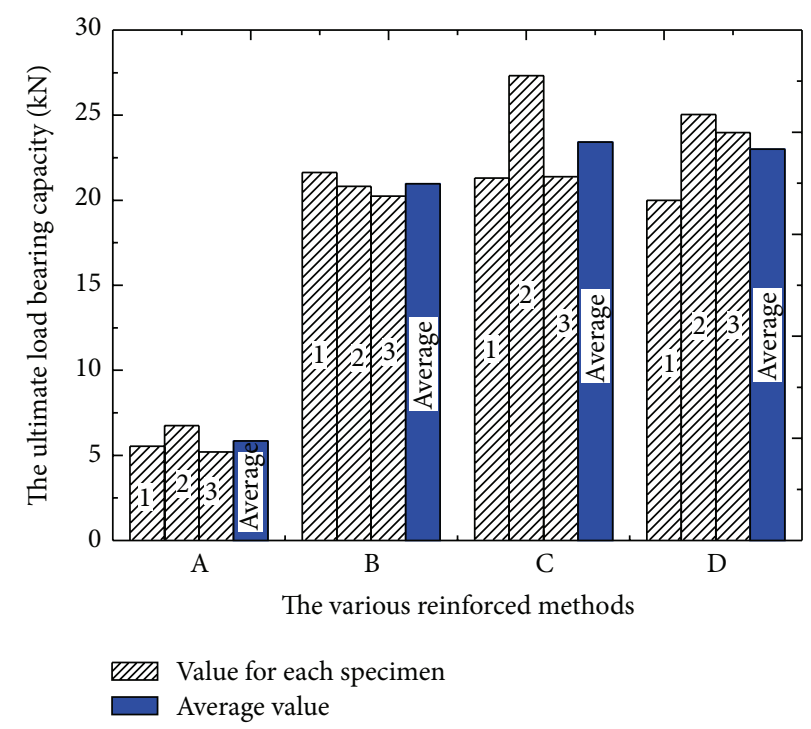

(c)

FIGURE 13: The plot of the ultimate bearing load of beams against various reinforcement methods for different CFRP length but with the same notch depth of $20 \mathrm{~mm}$. (a) CFRP length of $100 \mathrm{~mm}$, (b) CFRP length of $200 \mathrm{~mm}$, and (c) CFRP length of $350 \mathrm{~mm}$. A for without reinforcement, $\mathrm{B}$ for single-layer CFRP reinforcement, $\mathrm{C}$ for two-layer CFRP reinforcement, and D for single-layer CFRP reinforcement using U-shaped caps at the plate ends.

The shear stress at the end of the carbon fiber plate reduced significantly with an increase in the length of the CFRP layer. The increased length relieved the stress concentration at the end, reduced the failure potential of the reinforced structure at the end, and increased the bearing capacity of the structure.

\subsection{Effect of Reinforcement Methods on the Ultimate Bearing} Capacity of the Reinforced Beams. In this section, various reinforcement methods, including no CFRP reinforcement, single-layer CFRP reinforcement, two-layer CFRP reinforcement, and single-layer CFRP reinforcement using U-shaped caps at the plate ends, are discussed to investigate the effects of CFRP thickness and various bond methods on the ultimate bearing load of reinforced concrete beams. Even though the theoretical derivation in this paper does not consider different types of reinforcement methods, they are discussed in the viewpoint of the experimental findings in order to elucidate the role of various reinforcement methods on the CFRP-strengthening of concrete beams. A further research is expected to focus on the derivation of an analytical expression for the effect of various reinforced methods.

Figure 13 shows the influence of CFRP lengths of 100, 200 , and $350 \mathrm{~mm}$ and various reinforcement methods on the ultimate bearing capacity of the concrete beam for a notch depth of $20 \mathrm{~mm}$. When the CFRP layer was relatively short, such as 100 and $200 \mathrm{~mm}$ long, its thickness had insignificant 
influence on the ultimate bearing capacity of the reinforced structure. When the CFRP was $350 \mathrm{~mm}$ long, the ultimate bearing capacity of the reinforced structure bonded with two CFRP layers increased by $12 \%$ when compared with that of the reinforced structure bonded with one CFRP layer. The influence of wrapping the CFRP ends with the U-shaped caps also showed a similar trend. When the length of the CFRP was $100 \mathrm{~mm}$, the bearing capacity of the structure with the ends wrapped with U-shaped CFRP caps was considerably low. However, when the CFRP length increased to $200 \mathrm{~mm}$, the reinforcement effect of the CFRP-reinforced concrete beam was the most. With regard to the failure modes for the CFRPstrengthened concrete beams, as shown in Table 6, there were six test specimens with the U-shaped caps wrapped at the end of the CFRP layer. Out of the six, three followed the delamination failure mode, one followed the shear failure I mode, and two followed the shear failure II mode. Among the nine test specimens that used double layers of CFRP in the experiment, three specimens followed the shear failure II mode and six specimens followed the delamination failure mode. The possible reason for that is the usage of the Ushaped cap wrappings at the CFRP end fastened the CFRP on the bottom of the concrete beam much strongly compared to that in the cases with no cap wrapping. Even though the applied load increased sharply, CFRP could resist tension and shear deformation at the U-shaped cap. However, the interface between the CFRP and the concrete could not sustain the shear deformation and consequently led to the delamination failure. Nevertheless, with an increase in the thickness of CFRP, CFRP at the bottom of the concrete beam could withstand larger tensile stress at the end of the CFRP layer than a thinner CFRP layer would do, thus, relieving the tensile stress concentration at the end of the CFRP layer. However, as the load increased, the shear stress that transferred from the concrete beam to the interface also increased; the thicker interface enhanced its toughness, which results in an ease of peeling off of concrete from the concrete beam at the interface.

\section{Conclusions}

An experimental investigation was performed in this study on the failure mechanisms of concrete beams strengthened with a CFRP layer. The following conclusions were drawn:

(1) An analytical expression for the shear stress at the interface between concrete and CFRP was derived. The shear stress was found to be the key factor affecting the failure mode of the reinforced concrete beams. A parametric analysis for the effects of the length and the thickness of the CFRP layer was made for predicating the failure mode. Theoretical methods for calculating the ultimate load capacity of CFRPstrengthened beams were also presented.

(2) Four failure modes were observed in the experiment, namely, brittle fracture mode, shear failure I mode, shear failure II mode, and delamination failure mode. The failure mechanism for concrete beam without CFRP showed the brittle fracture mode; the concrete beam strengthened with shorter CFRP layer
$(100 \mathrm{~mm})$ showed the shear failure I mode; the concrete beam with long CFRP layer $(200 \mathrm{~mm})$ showed the shear failure II; and the beams with the longest CFRP layer $(350 \mathrm{~mm})$ showed the delamination failure mode.

(3) The length of the CFRP layer affected the ultimate load capacity of the CFRP-strengthened concrete beams. When CFRP length was $100 \mathrm{~mm}$ long, the ultimate load capacity is increased by 1.81 2.27 times compared to that of the nonreinforced concrete beams. It can even be increased by 3.35 3.97 and 3.61 5.76 times compared to that of nonreinforcement beams when the length of the CFRP layer was $200 \mathrm{~mm}$ and $350 \mathrm{~mm}$, respectively.

(4) When the CFRP layer was relatively short, its thickness had insignificant influence on the ultimate bearing capacity of the reinforced beam. However, when the CFRP length was $350 \mathrm{~mm}$, the ultimate bearing capacity of the concrete beam bonded with two CFRP layers increased by $12 \%$ compared to that of the beam bonded with one CFRP layer. The influence of the wrapping of the CFRP ends with the U-shaped caps on the ultimate bearing capacity of the structure also showed similar trend. When the length of the CFRP layer was $100 \mathrm{~mm}$, the bearing capacity of the structure with the ends wrapped with the U-shaped CFRP caps was considerably low. However, when the CFRP length increased to $200 \mathrm{~mm}$, the reinforcement effect of the concrete beam with the U-shape caps was the largest.

(5) Comparison between a theoretical analysis and the experimental observation showed a good agreement for the effect of the length and the thickness of the CFRP layer, as well as the ultimate load capacity for the CFRP-reinforced concrete beams. However, the effect of various reinforced methods on strengthening could not be explained by the theoretical derivation. A further research will focus on this topic.

\section{Conflict of Interests}

The authors declare no conflict of interests.

\section{Authors' Contribution}

Xia Huang is responsible for performing the theoretical derivation and has contributed to the writing of all the sections within paper. Jian Wang is working on experimental measurement and Feng Zhang has been in charge of data processing. Song-shan Niu is responsible for planning for experiment. Jun Ding is responsible for the whole research project.

\section{Acknowledgments}

This work is financially supported by the Natural Science Foundation of China (11302272), by the Natural Science Foundation of China (11272368), and by the 2013 Program 
for Innovation Team Building at Institutions of Higher Education in Chongqing (KJTD201319).

\section{References}

[1] T. Zhao, The New Technology for Retrofitting Concrete Structures with CFRP, Tianjing University Press, Tianjing, China, 1st edition, 2001.

[2] Y. Meng and B. Lu, The Reinforcement and Rehabilitaion for the Bridge, Chongqing University Press, Chongqing, China, 1st edition, 2005.

[3] J. Michels, R. Christen, and D. Waldmann, "Experimental and numerical investigation on postcracking behavior of steel fiber reinforced concrete," Engineering Fracture Mechanics, vol. 98, no. 1, pp. 326-349, 2013.

[4] H. C. Biscaia, C. Chastre, and M. A. G. Silva, "Nonlinear numerical analysis of the debonding failure process of FRP-to-concrete interfaces," Composites Part B: Engineering, vol. 50, pp. 210-223, 2013.

[5] M. C. Sundarraja and S. Rajamohan, "Strengthening of RC beams in shear using GFRP inclined strips-an experimental study," Construction and Building Materials, vol. 23, no. 2, pp. 856-864, 2009.

[6] A. K. M. A. Islam, "Effective methods of using CFRP bars in shear strengthening of concrete girders," Engineering Structures, vol. 31, no. 3, pp. 709-714, 2009.

[7] W. Edberg, D. Mertz, and J. Gillespie Jr., "Rehabilitation of steel beams using composites materials," in Proceedings of the ASCE 4th Material Engineering Conference, pp. 502-508, Washington, DC, USA, 1996.

[8] C. Mazzotti, M. Savoia, and B. Ferracuti, "An experimental study on delamination of FRP plates bonded to concrete," Construction and Building Materials, vol. 22, no. 7, pp. 1409-1421, 2008.

[9] K. Nakaba, T. Kanakubo, T. Furuta, and H. Yoshizawa, "Bond behavior between fiber-reinforced polymer laminates and concrete," ACI Structural Journal, vol. 98, no. 3, pp. 359-367, 2001.

[10] A. M. Malek, H. Saadatmanesh, and M. R. Ehsani, "Prediction of failure load of $\mathrm{R} / \mathrm{C}$ beams strengthened with FRP plate due to stress concentration at the plate end," ACI Structural Journal, vol. 95, no. 2, pp. 142-152, 1998.

[11] H. Saadatmanesh and M. R. Ehsani, "RC beams strengthened with GFRP plates. Part I: experimental study," Journal of Structural Engineering, vol. 117, no. 11, pp. 3417-3433, 1991.

[12] H. Saadatmanesh and R. E. Mohammad, "RC beams strengthened with GFRP plates. Part II: analysis and parametric study," Journal of Structural Engineering, vol. 117, no. 11, pp. 3434-3455, 1991.

[13] V. Sierra-Ruiz, J.-F. Destrebecq, and M. Grédiac, “The transfer length in concrete structures repaired with composite materials: a survey of some analytical models and simplified approaches," Composite Structures, vol. 55, no. 4, pp. 445-454, 2002.

[14] O. Buyukozturk, O. Gunes, and E. Karaca, "Progress on understanding debonding problems in reinforced concrete and steel members strengthened using FRP composites," Construction and Building Materials, vol. 18, no. 1, pp. 9-19, 2004.

[15] P. Colombi, "Reinforcement delamination of metallic beams strengthened by FRP strips: fracture mechanics based approach," Engineering Fracture Mechanics, vol. 73, no. 14, pp. 1980-1995, 2006.
[16] A. Benachour, S. Benyoucef, A. Tounsi, and E. A. A. Bedia, "Interfacial stress analysis of steel beams reinforced with bonded prestressed FRP plate," Engineering Structures, vol. 30, no. 11, pp. 3305-3315, 2008.

[17] T. L. Anderson, Fracture Mechanics: Fundamentals and Applications, CRC Press, Boca Raton, Fla, USA, 3rd edition, 2005.

[18] P. Y. Huang, Q. Q. Wang, L. F. Luo, and G. S. Zhang, "The experimental study on failure load for the reinforced concrete beams with FRP," Guangdong Highway Communications, vol. 66, pp. 254-257, 2001.

[19] Chinese Aeronautical Establishment, The Handbook for Stress Intensity Factors, Beijing Science Press, Beijing, China, 1981.

[20] S. S. Niu, The experimental study on concrete beams strengthened with CFRP [M.S. thesis], Chongqing University, Chongqing, China, 2002

[21] J. Ding, F. Wang, X. Huang, and S. Chen, "The effect of CFRP length on the failure mode of strengthened concrete beams," Polymers, vol. 6, no. 6, pp. 1705-1726, 2014.

[22] J. Ding, Crack failure study of CFRP reinforced concrete beams [M.S. thesis], Chongqing University, Chongqing, China, 2004.

[23] J. Ding, X. Huang, G. Zhu, S. Chen, and G. Wang, "Mechanical performance evaluation of concrete beams strengthened with carbon fiber materials," Advances in Materials Science and Engineering, vol. 2013, Article ID 572151, 9 pages, 2013. 

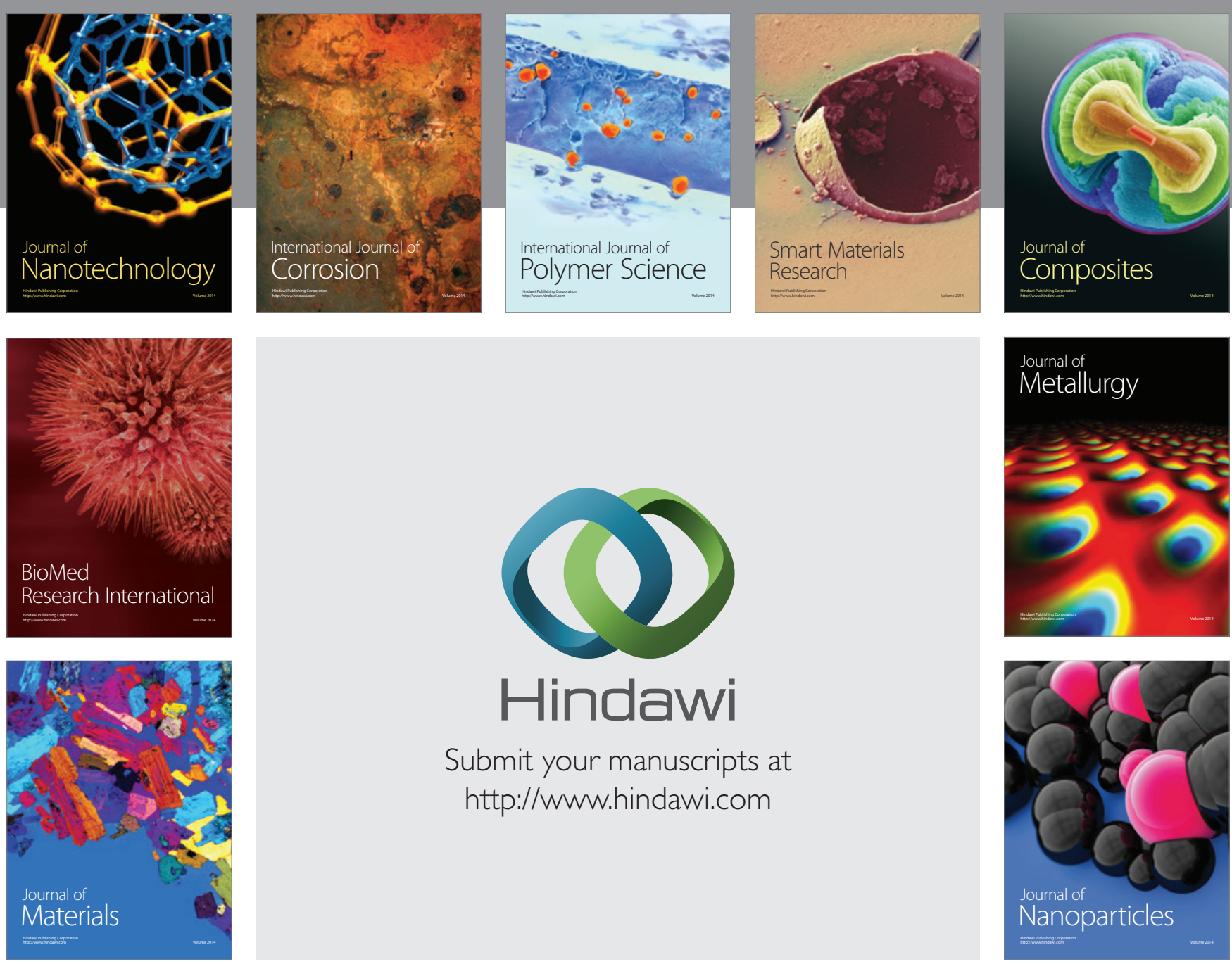

Submit your manuscripts at http://www.hindawi.com
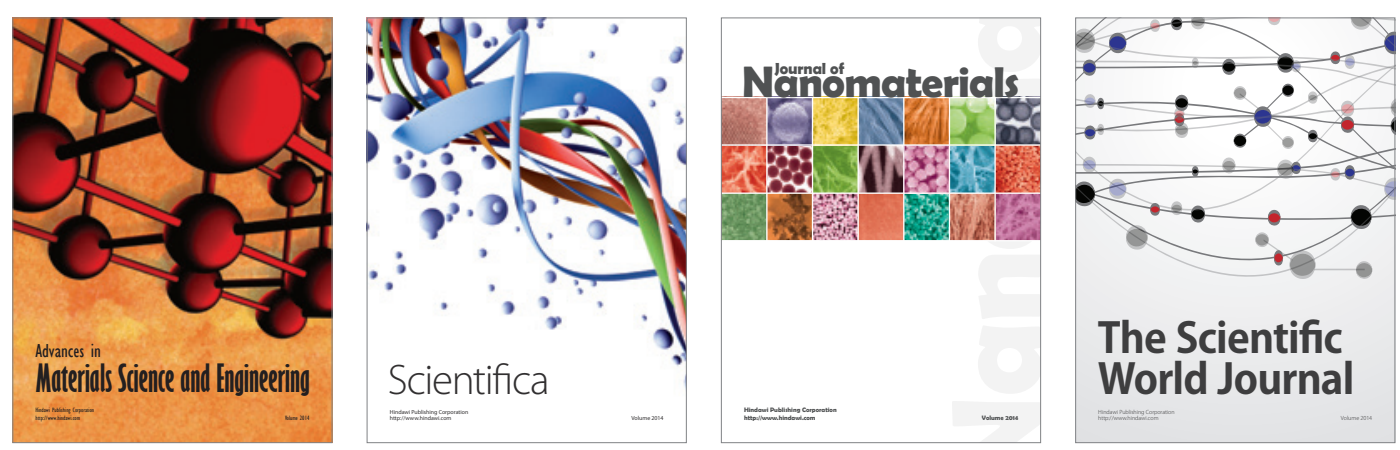

\section{The Scientific World Journal}
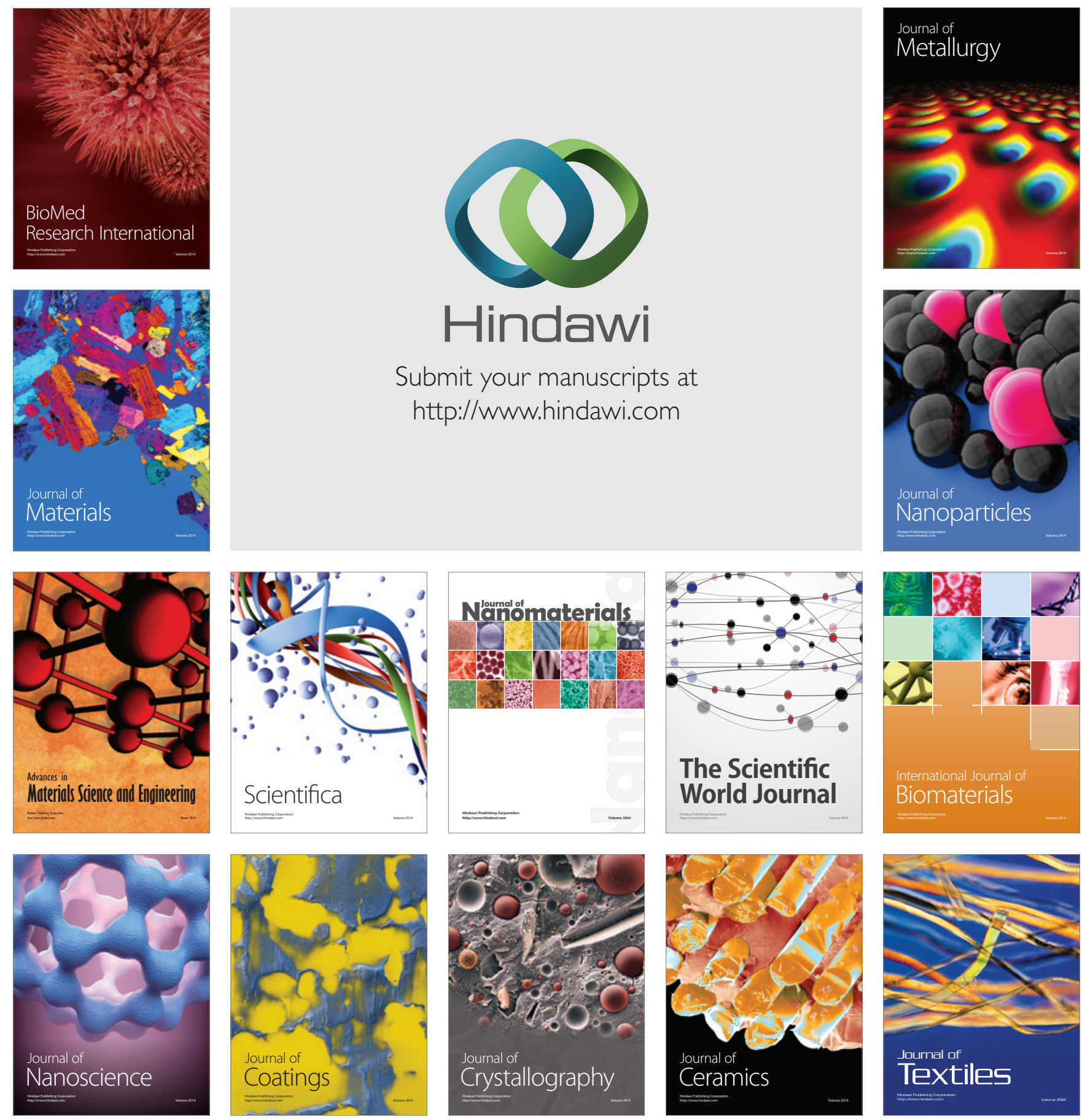